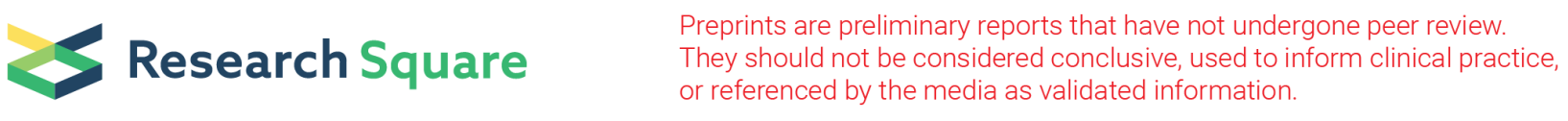

\title{
Atomistic wear mechanisms and deformation evolution in polishing
}

\section{Te-Hua Fang ( $\nabla$ fang@nkust.edu.tw)}

National Kaohsiung University of Science and Technology

Van-Thuc Nguyen

National Kaohsiung University of Science and Technology

\section{Research Article}

Keywords: Molecular dynamics, atomic level, material removal, wear mechanism, deformation behavior, tribology

Posted Date: November 24th, 2020

DOl: https://doi.org/10.21203/rs.3.rs-107099/v1

License: (1) This work is licensed under a Creative Commons Attribution 4.0 International License. Read Full License 


\title{
Atomistic wear mechanisms and deformation evolution in polishing
}

\author{
Van-Thuc Nguyen ${ }^{1,2}$, Te-Hua Fang, ${ }^{1, *}$ \\ ${ }^{1}$ Department of Mechanical Engineering, National Kaohsiung University of Science and Technology, \\ Kaohsiung 807, Taiwan \\ ${ }^{2}$ Institute of Research and Development, Duy Tan University, Danang 550000, Vietnam
}

${ }^{*}$ Corresponding author. Email address: fang@nkust.edu.tw (T.-H. Fang). 


\begin{abstract}
Our aim with this study was a new insight into the sub-nanoscale of polishing and provides the atomic view of the material removal and wear mechanisms by carrying out molecule dynamics simulation. We proposed and analyzed a model with a diamond abrasive particle that sliding or rolling on the surface of $\mathrm{GaN}$ workpieces. The authors investigated, step by step, the effects of polishing depths, speeds, abrasive sizes, and crystalline orientations on the wear mechanisms and material removal. The wear mechanisms of the sliding motion were adhering, ploughing, and cutting, depending on the depths. While the wear mechanisms of rolling motion are adhering and ploughing. Notably, in both stages of sliding and rolling, there is an existence of a critical point at $5.0 \AA$ depth when we considered the deformation behaviors. Below that critical point, the GaN workpiece will present an elastic deformation. From the aforementioned point, the workpiece would be plastically deformed. Besides, from $10 \AA$ depth, the dislocation began to appear and evolute simultaneously with the development of the maximum shear stress. The sliding motion on the Ga-face could remove a greater number of atoms than that of the $\mathrm{N}$-face. Moreover, direction [1-100] on Ga-face requesting more forces to polish than direction [11-20]. In conclusion, the main achievements that contribute to the field can be summarized as follows: the atomistic wear mechanisms of sliding and rolling motions, material removal, and the role of rolling motion at the sub-nanoscale during the ultrafine flat polishing process.
\end{abstract}

Keywords: Molecular dynamics, atomic level, material removal, wear mechanism, deformation behavior, tribology. 


\section{Introduction}

In the past several decades, Gallium nitride $(\mathrm{GaN})$ has played an important role in semiconductor technology due to its wide bandgap, high-temperature resistance, and high voltage resistance [1-3]. Therefore, $\mathrm{GaN}$ is a favorite selection for microelectronic devices, $5 \mathrm{G}$ networks devices, light-emitting diodes (LEDs), laser diodes, and radiofrequency devices [4,5]. Notably, power GaN technology exhibits the highest performance efficiency comparing to other popular materials, for instance, silicon material, promising a revolution in the power conversion and electrification technology [6,7]. GaN thin film can be produced by the epitaxial process on silicon carbide, sapphire, and GaN substrates [8]. A substrate made from $\mathrm{GaN}$ can create the best $\mathrm{GaN}$ epitaxial layer as it could limit the presence of crystalline defects [9].

This field is maturing since the semiconductor processes require a damage-free and mirror-like surface of wafers [10]. Thus, a wafer needs to go through a variety of surface processes such as grinding, lapping, and chemical mechanical polishing (CMP) [11]. However, the extraordinarily high hardness and super chemical inertness of GaN make challenges in achieving both a super flat surface and a high material removal rate (MRR) [12-14]. Many researchers have tried to find a suitable solution to address this challenge. Evidently, Aida et al. [15] reported that extremely small surface roughness of $0.18 \mathrm{~nm}$ could be achieved with a very low MRR of $17 \mathrm{~nm} / \mathrm{h}$. Xu et al. [16] obtained a smoother $0.0518 \mathrm{~nm}$ surface roughness and a better MRR of $66.9 \mathrm{~nm} / \mathrm{h}$ by using a metal catalyst in an acidic slurry. Besides, Wang et al. [17] reported an excellent $0.065 \mathrm{~nm}$ surface roughness and a high MRR of $103 \mathrm{~nm} / \mathrm{h}$ by using $\mathrm{H}_{2} \mathrm{O}_{2}-\mathrm{SiO}_{2}$-based slurry. While Nelabhotla et al. [18] achieved a higher MRR of $142 \mathrm{~nm} / \mathrm{h}$ by optimizing the CMP parameters in a $\mathrm{KMnO}_{4} / \mathrm{Al}_{2} \mathrm{O}_{3}$ slurry. In general, accomplishing a better surface roughness at the same time with high MRR is always a critical challenge in CMP technology. Therefore, prior researchers have conducted not only experiment but also modeling studies to optimize this technology $[19,22]$.

Molecular dynamics (MD) simulation is a popular computational technique to imitate nanoscale systems [23-25]. MD method could investigate dynamic characteristics by calculating Newton's equations of motions. Therefore, this method is widely used in studying the CMP operations, surveying the atomic level of polishing [26-28]. There are some authors consider the chemical reaction [29,30], while others survey the mechanical feature of the CMP process [31-33]. In fact, Shi et al. [34] pointed out that sliding motion could generate superior quality surface and 
increase efficiency during the CMP operation. Si et al. [35] reported that both sliding and rolling movements play major parts in the material removal mechanism. Besides, Zhang et al. [36] observed a phase transformation phenomenon of the silicon substrate polished by a diamond abrasive. However, these previous studies only focused on the nanoscale level of deformation and material removal despite prior experimental researches have reported the sub-nanoscale of polishing [15-17]. In particular, hardly any studies have carefully considered the sub-nanoscale deformation and removal in spite of its central role in creating an ultra-smooth surface. Hence, investigating the sub-nanoscale of material removal is critical, especially for extremely hard material like GaN.

The purposes of this paper are to find out the wear mechanisms and atomic removal at the subnanoscale. Moreover, the paper also wants to provide a more insightful understanding of the subnanoscale deformation behaviors and wear mechanisms. We have investigated the effect of this scale of polishing corresponding to the final steps of ultrafine polishing. To illuminate this uncharted area, we examined the polishing process of a diamond abrasive that slides or rolls on a monocrystalline GaN substrate at the sub-nanoscale by using MD simulation.

In the remainder of this paper, Section 2 demonstrates the modeling and the computational method. The diamond abrasive moved in two-body contact or sliding, and three-body contact or rolling types. The workpiece is GaN. We discuss the effects of the sliding depths and sliding speeds on the force, surface morphology, subsurface damage, stress, temperature, kinetic energy, dislocation, and material removal in Section 3.1. Section 3.2 investigates the rolling motion, while Section 3.3 mentions some realistic CMP parameters such as the abrasive sizes and crystalline orientations. Finally, Section 4 concludes this paper.

\section{Results}

\subsection{Two-body contact polishing}

To simulate the CMP process, in this section, the abrasive experienced a two-body contact or slid on the aforementioned range depths and speeds. Figs. 3(a)-(f) represent the force diagram at different polishing depths at $1.0 \AA$ /ps in the sliding motion. In general, increasing the polishing depth leads to increasing the thrusting force $\left(F_{y}\right)$ and the cutting force $\left(F_{x}\right)$. When considering the 
cutting force, the force diagrams can be distinguished both two types: the first type and the second type. The first type corresponds with $0.5 \AA-3.0 \AA$ depths, having nearly zero cutting forces, as shown in Figs. 3(a)-(d). The cutting force varies approximately zero because the abrasive only slightly glided over the workpiece surface without cutting anything as the polishing depths were too small. While the thrusting force $\left(\mathrm{F}_{\mathrm{y}}\right)$ increased as the abrasive move toward and touches the workpiece. Then, it reached a stable value and finally reduced as the abrasive passes by the GaN workpiece. The second one corresponds with $5.0 \AA$ A-10 Å depths, having the greatly higher cutting forces, as shown in Figs. 3(e)-(f). The absolute value of both scratching force and thrusting force increased gradually, and then reached stable values. Finally, the forces reduced as the abrasive passed through the GaN workpiece. The cutting force in the second one obtains an appreciable value comparing to the first type because with a deeper depth, the abrasive starts to penetrate the workpiece. Hence, there is a critical point at $5.0 \AA$ depth between these two types.

Figs. 4(a)-(f) show the structure change and surface morphology of the workpiece at the different polishing depths at $1.0 \AA \mathrm{A} / \mathrm{ps}$ in the sliding motion. Generally, the deeper depth is, the deeper the groove appears. Notably, like the force diagrams case, when considering the deformation behaviors, there is also a critical point at $5.0 \AA$ depth. At $0.5 \AA-3.0 \AA$ depths, the workpiece appeared no plastic deformations. There were only elastic deformations, as shown in Figs. 4(a)-(d). Therefore, the workpiece atoms across the pathway mostly preserved their crystalline structure. These are the reasons why the cutting force values, in this case, were very small, as illustrated in Figs. 3(a)-(d). However, at $5.0 \AA-10 \AA$ depths, the plastic deformation appeared, as presented in Figs. 4(e)-(f). At this case, the cutting force reached a greatly higher value comparing to the lower depth cases, as shown in Figs. 3(e)-(f). The crystalline structure of some workpiece atoms along the pathway was transformed into the amorphous state. There was the appearance of the subsurface damages (SSD) beneath the polishing surface. In addition, the deeper depth creates a deeper SSD.

Figs. 5(a)-(f) present the distribution of von Mises stress of the workpiece at different depths of polishing at $1.0 \AA ̊ \mathrm{ps}$ in sliding motion. Overall, the high-value zone of von Mises stress become wider and greater as increasing the depth. Interestingly, the presence of a critical point at $5.0 \AA$ still appeared in this case. Below this point, as shown in Figs. 5(a)-(d), despite there were some areas with a high-value of von Mises stress, but it would disappear as the abrasive passes by, 
indicating the elastic deformation. However, from this point and above, as shown in Figs. 5(e)-(f), there was residual stress appearing permanently along the pathway, indicating the plastic deformation. Moreover, at 5.0-10 ̊̊ depths, pile-up appeared, while at 0.5-3.0 Å depths, it did not exist. The deeper depth generated the higher pile-up, a similar result discussed by Wang et al. [45].

Figs. 6(a)-(f) represent the distribution of temperature of the workpiece at different polishing depths at $1.0 \AA \mathrm{A} / \mathrm{ps}$ in sliding motion. Below the critical point of $5.0 \AA$ depth, at $0.5 \AA-3.0 \AA$ depths, the temperature at the contact zones did not rise clearly because the interaction between the abrasive and the workpiece was not strong enough, as shown in Figs. 6(a)-(d). However, higher than the point of $5.0 \AA$ depth, the temperature at the contact zones rose clearly because the abrasive effectively transferred its kinetic energy into the workpiece, as shown in Figs. 6(e)-(f). From 5.0 $\AA$-10 ̊ depths, increasing the depth produced a higher and wider value of the high-temperature zone.

To further understand the propagation of deformation, we analyzed shear stress and dislocation. Figs. 7(a)-(b) show the maximum shear stress and dislocation mobility of the workpiece at $10 \AA$ depth and $1.0 \AA$ /ps. Below $10 \AA$ depth, the shear stress value was small and there was no dislocation, indicating a high-quality surface. Figs. 7(a) shows that the high-value zone of shear stress rose at the front side of the abrasive. When the abrasive slid over the workpiece, this zone was separated into two parts. The first one appeared beneath the abrasive, while the other gradually grew along the workpiece surface. When some atoms were extruded at the end of the workpiece, the second one was gradually disappeared as the shear stress was released. This extension part was a shear band that appeared during the plastic deformation in a crystalline structure. Besides, the shear stress developed simultaneously with the mobility of the dislocation. Fig. 7(b) presents the dislocation mobility of the workpiece. Initially, there was no dislocation when the deformation was not accumulated enough. Then, the dislocation raised when the high-value of the shear stress zone began to be separated. Finally, when the abrasive passed by the workpiece, some dislocations still existed. The position of the dislocation was related to the second part of the high-value zone of shear stress, indicating the close relationship of the evolution of the stress and the deformation.

We describe the results of the total dislocation length during the sliding process at $10 \AA$ depth and $1.0 \AA$ Àps demonstrated Fig. 8. Similar to Fig. 7(b), it needed a while to accumulate the deformation before the dislocation appears. Then, the dislocation length raised rapidly and 
achieved the highest value of $89.3 \AA$ at 150 ps. The dislocation length reduced suddenly as the shear band appeared and released the stress. Finally, there were still some dislocations after the abrasive passing by the workpiece.

Fig. 9 exhibits the total kinetic energy diagram and its distribution at a variety of velocities at $5.0 \AA$ depth. The results showed that rising the sliding velocity led to the improvement in the kinetic energy due to the higher rate of impact between the abrasive and the workpiece [46]. Increasing the sliding velocity also caused more atoms in front of the abrasive to rise their kinetic energies.

Table 1. shows the number of atoms removed at a variety of polishing depths and velocities in sliding motion. The average numbers of removed atoms were 0.7, 1, 8.7, 1.3, 274.7, and 1653 atoms corresponding to $0.5 \AA, 1.0 \AA$, $2.0 \AA, 3.0 \AA$, $5.0 \AA$, and $10 \AA$ depths, respectively. Thus, increasing the depth mostly enlarged the number of atoms removed. At 0.5-3.0 $\AA$ depths, the number of removed atoms was minor, indicating the no-wear or adhering mechanisms. At $5.0 \AA$ depth, a cluster of atoms was removed, with a pile-up appeared during the sliding process, as shown in Fig. 5(e), indicating a ploughing mechanism. Increasing the sliding speed at 5.0 A depth led to a rapid improvement in the number of removed atoms. Because at a higher sliding speed, the kinetic energy is higher enough to impact the atomic cluster, causing a higher rate of MRR. At $10 \AA$ depth, a great number of atoms was removed. Besides, a higher pile-up appeared during the sliding process, as shown in Fig. 5(f), pointing out a cutting regime. Additionally, improving the velocity at $10 \AA$ depth did not lead to an adequate change in the number of atoms removed, a similar pattern of results was obtained in Agrawal et al. report [47].

A further finding is that according to Zhang et al. [48], in a sliding motion, wear mechanism type depends on how much the depth is. Gradually increasing the depth will cause no-wear mechanism with pure elastic deformation and without material removal, adhering mechanism with atomic removal, ploughing mechanism with atomic cluster removal, and cutting mechanism. However, as shown in Table. 1, at 0.5-3.0 $\AA$ depths, it is notable that with ultra-fine polishing depths and pure elastic deformation, which is similar to the no-wear mechanism, some atoms were still removed. Thus, there was almost no no-wear mechanism. In this type of motion, the removal and wear mechanisms are adhering, ploughing, and cutting. 
In general, there is a critical point between elastic and plastic deformations. Below this critical point of $5.0 \AA$ A depth, the workpiece will suffer an elastic deformation. When the abrasive surpasses this point, the workpiece will be plastically deformed. The number of atomic removed also depends on this critical point. With a polishing depth larger than $5.0 \AA$, the number of atoms removed is greatly increased. At $10 \AA$ depth, the dislocation begins to appear and evolve simultaneously with the development of the maximum shear stress. The appearance of the shear band will help reduce the dislocation. The wear mechanisms are adhering, ploughing, and cutting, depending on the polishing depth.

\subsection{Three-body contact polishing}

Three-body contact or rolling movement is an important type of movement. Therefore, researching the removal mechanism at the atomic level removal is critical to understand the removal process of $\mathrm{GaN}$. In this section, the abrasive rolls at a variety of depths and speeds. The abrasive rolls at 25-100 rad/ns with different rolling depths from $0.5 \AA$ to $10 \AA$.

Our results demonstrated that the force diagram at a variety of polishing depths when the abrasive rolls at $50 \mathrm{rad} / \mathrm{ns}$, and moves at $1.0 \AA / \mathrm{ps}$ in a rolling motion showed Figs. 10(a)-(f). The results revealed that improving the polishing depth led to increasing the value of the thrusting force $\left(F_{y}\right)$ and the cutting force $\left(F_{x}\right)$, a similar result with the sliding motion. Initially, the thrusting force started to raise its value as the abrasive touches the workpiece. Then, the thrusting force achieved a stable value before reducing as the abrasive passing through the workpiece. Notably, similar to the sliding motion, there was also a critical point at $5.0 \AA$, where the cutting force began to increase its value. Below this point, the value of the cutting force oscillated around zero value, as shown in Figs. 10(a)-(d). This was because the polishing depth was too small, thus, the abrasive only slightly rolled over the workpiece surface. From this critical point and above, the cutting force gained a greater value due to the deeper penetration of the abrasive into the workpiece, as shown in Figs. 10(e)-(f).

This is a notable finding in the understanding of the structure change of the workpiece at different polishing depths when the abrasive rolls at $50 \mathrm{rad} / \mathrm{ns}$ and moves at $1.0 \AA / \mathrm{ps}$ in the rolling motion (see Figs. 11(a)-(f)). Overall, the deeper depth was, the deeper the groove appears. 
Remarkably, below the critical point of $5.0 \AA$ depth, there was no plastic deformation, which was similar to the sliding motion, as shown in Figs. 11(a)-(d). Moreover, the number of workpiece removed atoms was dramatically higher than the sliding motion, indicating an efficiency adhering mechanism. From the critical point of $5.0 \AA$ A, the plastic deformation happened, as shown in Figs. 11(e)-(f). The crystalline structure of the workpiece across the pathway was transformed into an amorphous state. The SSD appeared in these depths with a stronger intensity than the sliding motion. Hence, in the rolling motion, the stirring effect of the abrasive could cause deeper damage than the sliding one.

According to a common idea [48], in a rolling motion, wear mechanism relies on the depths. Gradually increasing the depth caused respectively no-wear mechanism with pure elastic deformation and without material removal, condensing mechanism with phase transformation and without material removal, adhering mechanism with atomic removal, and ploughing mechanism with atomic cluster removal. However, it was very interesting that with ultra-fine polishing depth and pure elastic deformation that was similar to no-wear and condensing mechanisms, there were still few atoms sticking around the abrasive. It proved that in the rolling motion, the adhering mechanism will happen even if polishing with a sub-nanoscale and pure elastic deformation in the rolling motion. Therefore, in the rolling motion, the removal and wear mechanisms were adhering and ploughing. Overall, adhering and ploughing mechanisms can appear in a rolling motion while adhering, ploughing, and cutting mechanisms appear in a sliding motion, as shown in Fig. 12. This means that different from the micro-level view, at the nanoscale and sub-nanoscale of removing, there are no no-wear and condensing mechanisms. There are adhering, ploughing, and cutting mechanisms that can present in two-body contact or three-body contact.

The distributions of von Mises stress of the workpiece at a variety of polishing depths when the abrasive rolls at $50 \mathrm{rad} / \mathrm{ns}$ and moves at $1.0 \AA / \mathrm{ps}$ in the rolling motion are illustrated Figs. 13(a)-(f). Increasing the depth resulted in a greater and wider of the high-stress zone. In addition, there were some high-value of von Mises stress at 0.5 $\AA-3.0 \AA$ depths, but it would disappear as the abrasive passes by, indicating a mostly elastic deformation, as shown in Figs. 13(a)-(d). At 5.0 $\AA-10 \AA$ depths, along the pathway, some atoms had a high value of residual stress because they suffer a plastic deformation. Therefore, there was also a critical point at $5.0 \AA$ depth. There was 
no pile up as the sliding one because the removed atoms were adhered to the abrasive surface and did not accumulate in front of the abrasive, as shown in Figs. 13(e)-(f).

The hydrostatic stress distribution of the workpiece at a variety of polishing depths when the abrasive rolls at $50 \mathrm{rad} / \mathrm{ns}$, moves at $1.0 \AA / \mathrm{ps}$ in the rolling motion is shown in Figs. 14(a)-(f). The results indicated that improving the depth would create higher hydrostatic stress. At $10 \AA$ depths, the atoms along the pathway had the compression and tension sequentially, pointing out the adhering effect of the abrasive to the workpiece atoms, as shown in Figs. 14(f)-(f1). When the abrasive rotated, besides the pressing effect right below the abrasive, the abrasive adhered to the workpiece atoms, causing a pulling effect and a tension stress at the backside of the abrasive. The workpiece atoms were also pressed down, at the front side, caused the pushing effect and the compression stress on the workpiece.

Figs. 15(a)-(f) present the distribution of the workpiece temperature at a variety of polishing depths when the abrasive rolls at $50 \mathrm{rad} / \mathrm{ns}$, moves at $1.0 \AA / \mathrm{ps}$ in the rolling motion. Generally, when the abrasive penetrated deeper into the workpiece, it would generate a higher value of the temperature. At $0.5 \AA-3.0 \AA$ depths, the temperature at the contact zones did not rise clearly as the interaction between the abrasive and the workpiece was not strong, as shown in Figs. 15(a)-(d). At $5.0 \AA-10 \AA$ depths, the temperature at the contact zones rose strongly as the abrasive transferred efficiently its kinetic energy to the workpiece, as shown in Figs. 15(e)-(f). The difference indicated the rolling motion to the sliding motion was the high-temperature zones in the workpiece separated into two zones.

For a semiconductor material, dislocation is a special concern as it has a significant effect on mechanical, optical, and electrical properties. Figs. 16(a)-(b) show the maximum shear stress and dislocation mobility at $10 \AA$ depths, rolling at $50 \mathrm{rad} / \mathrm{ns}$ and moving at $1.0 \AA / \mathrm{ps}$. Fig. 16(a) shows that the high-value zone of shear stress existed at the front side of the abrasive. When the abrasive rolled over the workpiece, this zone was gradually separated into two parts. The first part appeared under the abrasive, while the second part developed along the workpiece surface. When a group of atoms was extruded at the end of the workpiece, the second part was gradually disappeared as the shear stress was released. Fig. 16(b) presents the dislocation mobility of the workpiece in the rolling motion. Initially, there was no dislocation when the abrasive did not deform the workpiece enough. Thereafter, it appeared as the high-value of the shear stress zone began to be separated. 
Then, the dislocation moved along the workpiece surface toward the end of the workpiece synchronously with the movement of the second part of the high-value zone of shear stress. Finally, when the abrasive passed by the workpiece, some small amounts of dislocations still appeared. The position of the dislocation was related to the second part of the high-value zone of shear stress, which indicated the close relationship between stress and deformation.

From the results, it is clear that Fig. 17 exhibits the total dislocation length during the rolling process at $10 \AA$ depths, rolling at $50 \mathrm{rad} / \mathrm{ns}$ and moving at $1.0 \AA / \mathrm{ps}$. After a while, the dislocation started to appear when the deformation accumulates highly enough. Then, the dislocation length increased greatly, obtaining the highest value of $57.7 \AA$ at 95 ps. After that, the dislocation length declined dramatically as the extension part appeared and released the stress and deformation. Finally, there were still some small amount of dislocations after the abrasive rolling through the workpiece. Comparing to sliding, the rolling motion created shorter dislocation during the polishing process, and the residual dislocation was also smaller.

The kinetic energy diagram and its distribution at different rolling velocities at $5.0 \AA$ depth are displayed Fig. 18. Overall, the total kinetic energy of $50 \mathrm{rad} / \mathrm{ns}, 100 \mathrm{rad} / \mathrm{ns}$, and $200 \mathrm{rad} / \mathrm{ns}$ were mostly similar. Particularly, the kinetic energy distribution indicated that the $100 \mathrm{rad} / \mathrm{ns}$ case had the lowest value, while the $200 \mathrm{rad} / \mathrm{ns}$ case reaches the highest value. Because at $100 \mathrm{rad} / \mathrm{ns}$ the rolling speed was equal to the moving speed of the workpiece, thus, the abrasive only slightly rolled over the workpiece surface. With a difference in the relative motion, at $50 \mathrm{rad} / \mathrm{ns}$, the rolling speed of the abrasive was lower than the moving speed. It means that the effect of sliding motion still existed, causing stronger kinetic energy than at $100 \mathrm{rad} / \mathrm{ns}$. While at $200 \mathrm{rad} / \mathrm{ns}$, the rolling speed of the abrasive was higher than the moving speed, therefore, the rolling motion of the abrasive caused more friction effect on the workpiece surface.

Table 2. demonstrates the number of atoms removed at a variety of depths and speeds in the rolling motion. The average numbers of workpiece atoms removed were 64, 115.3, 228, 367, 640, and 990.3 atoms corresponding to the $0.5 \AA, 1.0 \AA, 2.0 \AA, 3.0 \AA, 5.0 \AA$, and $10 \AA$ depths, respectively. Increasing the rolling depth led to linearly increasing the number of atoms removed. Especially, at 0.5-3.0 $\AA$ depths, the numbers of workpiece atoms removed were significantly higher when comparing to the sliding motion. The reason was that the adhering effect in the rolling motion was more effective than the sliding one as there was more surface area taking part in the 
adhering process, as shown in Figs. 11(a)-(f). Notably, increasing the rolling speed at 0.5-1.0 depths led to a surge in the number of atoms removed. While the lowest number of atoms removed did not correspond to the lowest rolling speed at $50 \mathrm{rad} / \mathrm{ns}$ but at $100 \mathrm{rad} / \mathrm{ns}$ at 2.0-5.0 $\AA$ depths. Because at 2.0-5.0 $\AA$ depths, the difference between the rolling and the sliding motions was smallest, as shown in Fig. 18. At $50 \mathrm{rad} / \mathrm{ns}$, the sliding effect was still present, causing a stronger removal. However, at 0.5-1.0 $\AA$ depths, the polishing depths were too small to be impacted by the sliding movement. At $5.0 \AA$ depth, the numbers of atoms removed in rolling motion were also greater than the sliding one. However, the speed of increasing the removed atoms was slower than the previous depths as the abrasive surface suffered a saturated phenomenon [49]. At $10 \AA$ depth, the numbers of atoms removed in rolling motion were smaller than the sliding one. The reason was the abrasive surface saturated, in this case, and the workpiece atoms were not completely extruded as the sliding motion. If the extrusion part was not considered, the rolling motion would achieve a greater number of workpiece atoms removed.

In summary, there is a critical point of $5.0 \AA$ depth between elastic and plastic deformations. Lower than this point, the material is elastically deformed. From this point and above, the material is plastically deformed. Therefore, elastic is the principal deformation type at the sub-nanoscale of polishing. At $10 \AA$ depth, dislocation starts to appear and evolve simultaneously with the development of the maximum shear stress. Besides, from $5.0 \AA$ depth and below, the removal ability of the rolling motion is much greater than the sliding one. Thus, the rolling motion plays a vital role in polishing at the atomic level of polishing. In rolling motion, the wear mechanisms are adhering and ploughing, depending on the polishing depth. The tribology behaviors of sliding and rolling do not have a no-wear and condensing mechanisms.

\subsection{Effect of abrasive size and orientation}

In a CMP process, the abrasive varies in a range of sizes, while the wafer always rotates around its center. Therefore, in this section, the abrasive size varies from 30 - $50 \AA$ to identify the effect of abrasive size to the material removal and deformation. Furthermore, the anisotropic characteristic of the GaN substrate is also considered by simulating with not only [11 $\overline{2} 0]$ direction and Ga-face but also [1 100$]$ direction and $\mathrm{N}$-face. 
Our results casts a light on the total force diagram of different abrasive sizes when it slides with $1.0 \AA / \mathrm{ps}$ at $5.0 \AA$ depth. The results presented that increasing the abrasive size led to larger forces (see Fig. 19). The increasing rate of the total forces from $30 \AA$ to $40 \AA$ abrasive was much higher than that of from $40 \AA$ to $50 \AA$. Thus, at the same depth, a smaller abrasive could remove the workpiece atoms more gentle than the bigger one, leading to a better polishing surface [50].

The morphology of the workpiece surface and distribution of von Mises stress of different abrasive sizes when the abrasive slides with $1.0 \AA$ ps at $5.0 \AA$ depth are shown in Figs. 20(a)-(c). The smaller abrasive caused the higher protrusion on the groove edge as the abrasive shape became sharper. Besides, the high-stress zone became more focused right beneath the abrasive as increasing the abrasive radius because the bigger abrasive intended to press the workpiece atoms down than ploughing it up. Moreover, the numbers of workpiece atoms removed were 394, 191, and 151 atoms corresponding to 30,40, and $50 \AA$ abrasives, respectively. At an ultrafine depth, the number of workpiece atoms removed reduced when increasing the abrasive size as the tool was less sharp.

Figs. 21(a)-(c) presents the morphology of the workpiece surface and distribution of von Mises stress of different abrasive sizes when the abrasive rolls at $50 \mathrm{rad} / \mathrm{ns}$, moves with $1.0 \AA$ 解 at 5.0 $\AA$ depth. The results pointed out that the rotational motion of the abrasive did not produce protrusion and pile up as the sliding motion. Additionally, the high-stress area in the rolling motion was more focused right beneath the abrasive rather than in front of it as the sliding one. The numbers of workpiece atoms removed were 467, 574, and 768 atoms corresponding to 30, 40, and $50 \AA$ abrasives, respectively. The number of atoms removed increased when increasing the abrasive size as the surface area of the abrasive was correspondingly improved.

The total forces of different polishing directions and faces at $1.0 \AA$ /ps and $5.0 \AA$ depth are illustrated in Figs. 22(a)-(b). With the same Ga-face, direction [1100] required more forces than direction $[11 \overline{2} 0]$ in both sliding and rolling motions. With the same [11̄0] direction, sliding on $\mathrm{N}$-face required a lower force than on Ga-face, as shown in Fig. 22(a). However, with the same [1120] direction, rolling on N-face required similar forces to Ga-face, as shown in Fig. 22(b). Besides, the formation of a step-terrace structure was an indication to identify the high-quality surface of a GaN wafer after polishing [51,52]. The anisotropy of the GaN workpiece and the off- 
angle deflection could explain the formation of the step-terrace structure at an ultra-fine polishing process, in which the direction that required a slighter force to deform could be easier to polish.

It is worth discussing the results of surface morphology and distribution of von Mises stress of different sliding directions and faces, sliding at $1.0 \AA / \mathrm{ps}$, and $5.0 \AA$ depth (see Figs. 23(a)-(c)). With the same Ga-face, sliding in [1100] direction caused a broader amorphized zone along the pathway than the [11 $\overline{2} 0]$ direction, as shown in Figs. 23(a)-(b). Additionally, in [1 $\overline{1} 00]$ direction, the atoms were more concentrated on both sides of the pathway to cause higher protrusions rather than concentrated in front of the abrasive to create a high pile-up as the [1120] direction. With the same $[11 \overline{2} 0]$ direction, sliding in $\mathrm{N}$-face caused higher protrusions but lower pile-up than in Gaface, as shown in Figs. 23(b)-(c). Moreover, the high-stress zone in N-face case was much smaller than in Ga-face as the total force was smaller, as shown in Fig. 22(a). Besides, the numbers of workpiece atoms removed were 179, 191, and 58 atoms corresponding to [11̄00] direction/Gaface, $[11 \overline{2} 0]$ direction/G-face, and [1120] direction/N-face, respectively. Sliding with different directions did not create an adequate change in the removal of workpiece atoms. However, sliding on Ga-face removed a greater number of workpiece atoms removed than $\mathrm{N}$-face does.

The surface morphology and von Mises stress distribution of different rolling directions and faces, rolling at $50 \mathrm{rad} / \mathrm{ns}$, moving at $1.0 \AA / \mathrm{ps}$, and $5.0 \AA$ depth are shown in Figs. 24(a)-(c). The results showed that rolling in different directions and faces did not generate an appreciable change in surface morphology and von Mises stress distribution. The numbers of workpiece atoms removed were 612,574 , and 413 atoms corresponding to [1-100] direction/Ga-face, [11-20] direction/G-face, and [11-20] direction/N-face, respectively. Therefore, rolling on [1-100] direction/Ga-face removed the highest number of atoms while rolling on [11-20] direction/N-face removed the lowest number of atoms.

The ratio of the number of atoms removed between rolling and the sliding motions in different studies are shown in Table 3. In this study, we chose a $5.0 \AA$ depth case to compare with other papers. Zhong et al. [53] indicate a greatly lower comparing to this research ratio because they applied a fixed abrasive CMP following a polishing process with a fabric cloth pad. Other experimental studies [54-56] survey an entirely polishing process, in which the sliding motion is an important factor in the initial and middle steps, therefore, the ratio is lower than this research. 
However, if the final step of polishing with ultrafine is recreated by simulations [57,58], the rolling motion can present its advantages comparing to the sliding one in the material removal process.

Generally, the number of atoms removed in rolling motion increases as increasing the abrasive size as the surface area is improved. On Ga-face, direction [1100] demands more forces than direction $[11 \overline{2} 0]$ in both sliding and rolling motions. Interestingly, sliding with different directions does not make an adequate change in the number of workpiece atoms removed. However, sliding on Ga-face can remove a great number of atoms than $\mathrm{N}$-face.

\section{Discussion}

In this study, we present the polishing process of a diamond abrasive that slides or rolls on the $\mathrm{GaN}$ workpiece at the sub-nanoscale by MD simulation tools. The influences of polishing depths, speeds, abrasive size, and orientations on the wear mechanisms and material removal were carefully investigated. The wear mechanisms in sliding motion can be adhering, ploughing, and cutting, depending on the depth. While the wear mechanisms in rolling motion are adhering and ploughing. In both sliding and rolling motions, there is no no-wear mechanism. There was an existence of a critical point between elastic and plastic deformations at $5.0 \AA$ depth. The elastic deformation had to be the main deformation type at the sub-nanoscale of polishing. The appearance of the shear band would help reduce the dislocation.

Below 5.0 A depth, the removal ability of the rolling motion was significantly higher than that of the sliding one. However, higher than that point, the sliding motion presented a higher MRR. Therefore, the rolling motion plays a key role in polishing at the atomic level of polishing. Sliding on Ga-face could erase a greater number of atoms than N-face. Besides, rolling on [1100] direction/Ga-face removes the highest number of atoms while rolling on [1120] direction/N-face removed the lowest number of atoms. Sliding and rolling on different orientations and faces resulted in a different number of atoms removed. The results shed more light on wear mechanism, material removal, and deformation behavior at the sub-nanoscale, helping to achieve an ultrafine flat surface in polishing. 


\section{Methods}

The simulation model consists of a monocrystalline hexagonal GaN substrate with 160.8 A in length, $78.6 \AA$ in width, and $64.3 \AA$ in thickness, and a $40 \AA$ diamond abrasive, as shown in Fig.1. The diamond hardness is greatly higher than the $\mathrm{GaN}$ substrate, therefore, the diamond abrasive is handled as a stiff body. The polishing depths are in the range of $0.5 \AA$ to $1.0 \AA, 2.0 \AA$, $5.0 \AA$, and $10 \AA$ to survey the sub-nanoscale of wear mechanisms and material removal. In sliding motion, the moving speeds of the abrasive are between $0.5-2 \AA / p s$ or $50-200 \mathrm{~m} / \mathrm{s}$ in the $\mathrm{X}$-axis direction. In rolling motion, the abrasive turns at $25-100 \mathrm{rad} / \mathrm{ns}$ or $50-200 \mathrm{~m} / \mathrm{s}$, the abrasive moves along the horizontal $\mathrm{x}$-axis at a speed of $1.0 \AA \mathrm{A} / \mathrm{ps}$ at the same time.

The surface of the GaN substrate is the (0001) plane or c-plane, while the x-axis parallels to the $[11 \overline{2} 0]$ direction. Fig. 2 exhibits the radial distribution functions (RDF) diagrams of the substrate, indicating a hexagonal structure of GaN [37]. The peaks at $2.0 \AA$, $3.8 \AA$, and $4.9 \AA$ only describe the length of the Ga-N bonds, while the other peaks represent the Ga-N, Ga-Ga and N-N bonds.

This study carried out LAMMPS code [38] to simulate the model, using the NVE ensemble at a temperature of $300 \mathrm{~K}$, with 1.0 fs time step. The Ga-N interactions applied Stillinger-Weber potential $[39,40]$, while the N-C interactions used the BNC Tersoff potential $[41,42]$. The Ga-C implied the Lennard-Jones potential with $\sigma=3.2990 \AA$ and $\varepsilon=0.0565 \mathrm{eV}$ [43]. OVITO software is employed to observe and inspect the simulation results such as structure change, stress, dislocation [44]. 


\section{References}

[1] Utsumi, W., Saitoh, H., Kaneko, H., Watanuki, T., Aoki, K., \& Shimomura, O. (2003). Congruent melting of gallium nitride at $6 \mathrm{GPa}$ and its application to single-crystal growth. Nature materials, 2(11), 735-738.

[2] Denis, A., Goglio, G., \& Demazeau, G. (2006). Gallium nitride bulk crystal growth processes: A review. Materials Science and Engineering: R: Reports, 50(6), 167-194.

[3] Yuk, K., Branner, G. R., \& Cui, C. (2017, August). Future directions for GaN in 5G and satellite communications. In 2017 IEEE 60th International Midwest Symposium on Circuits and Systems (MWSCAS) (pp. 803-806). IEEE.

[4] Pearton, S. J., Abernathy, C. R., Overberg, M. E., Thaler, G. T., Onstine, A. H., Gila, B. P., ... \& Kim, J. (2002). New applications advisable for gallium nitride. Materials today, 5(6), 24-31.

[5] Baliga, B. J. (2013). Gallium nitride devices for power electronic applications. Semiconductor Science and Technology, 28(7), 074011.

[6] Chowdhury, D. (2020). Power Gallium Nitride Technology: The Need for Efficient Power Conversion. IEEE Electrification Magazine, 8(2), 6-10.

[7] Reusch, D., \& de Rooij, M. (2017, March). Evaluation of gate drive overvoltage management methods for enhancement mode gallium nitride transistors. In 2017 IEEE Applied Power Electronics Conference and Exposition (APEC) (pp. 2459-2466). IEEE.

[8] Qiu, P., Wei, H., An, Y., Wu, Q., Du, W., Jiang, Z., ... \& Song, Y. (2020). Plasmaenhanced atomic layer deposition of gallium nitride thin films on fluorine-doped tin oxide glass substrate for future photovoltaic application. Ceramics International, 46(5), 5765-5772.

[9] Huang, L., Liu, F., Zhu, J., Kamaladasa, R., Preble, E. A., Paskova, T., ... \& Davis, R. F. (2012). Microstructure of epitaxial GaN films grown on chemomechanically polished $\mathrm{GaN}$ (0001) substrates. Journal of crystal growth, 347(1), 88-94.

[10] Deng, H., Endo, K., \& Yamamura, K. (2015). Plasma-assisted polishing of gallium nitride to obtain a pit-free and atomically flat surface. CIRP Annals, 64(1), 531-534.

[11] Lee, H., Kasuga, H., Ohmori, H., Lee, H., \& Jeong, H. (2011). Application of electrolytic in-process dressing (ELID) grinding and chemical mechanical polishing (CMP) process for emerging hard-brittle materials used in light-emitting diodes. Journal of crystal growth, 326(1), 140-146.

[12] Shi, X., Zou, C., Pan, G., Gong, H., Xu, L., \& Zhou, Y. (2017). Atomically smooth gallium nitride surface prepared by chemical-mechanical polishing with $\mathrm{S} 2 \mathrm{O} 82-$-Fe2+ based slurry. Tribology International, 110, 441-450.

[13] Gong, H., Pan, G., Zhou, Y., Shi, X., Zou, C., \& Zhang, S. (2015). Investigation on the surface characterization of Ga-faced $\mathrm{GaN}$ after chemical-mechanical polishing. Applied Surface Science, 338, 85-91. 
[14] Ou, L. W., Wang, Y. H., Hu, H. Q., Zhang, L. L., Dong, Z. G., Kang, R. K., ... \& Shi, K. (2019). Photochemically combined mechanical polishing of $\mathrm{N}$-type gallium nitride wafer in high efficiency. Precision Engineering, 55, 14-21.

[15] Aida, H., Doi, T., Takeda, H., Katakura, H., Kim, S. W., Koyama, K., ... \& Uneda, M. (2012). Ultraprecision CMP for sapphire, $\mathrm{GaN}$, and $\mathrm{SiC}$ for advanced optoelectronics materials. Current Applied Physics, 12, S41-S46.]

[16] Xu, L., Pan, G., Zou, C., Shi, X., \& Liu, Y. (2014, November). Atomically smooth gallium nitride surfaces generated by chemical mechanical polishing with non-noble metal catalyst $(\mathrm{Fe}-\mathrm{N} \mathrm{x} / \mathrm{C})$ in acid solution. In Proceedings of International Conference on Planarization/CMP Technology 2014 (pp. 237-241). IEEE.

[17] Wang, J., Wang, T., Pan, G., \& Lu, X. (2015). Mechanism of GaN CMP based on H2O2 slurry combined with UV light. ECS Journal of Solid State Science and Technology, 4(3), P112.

[18] Nelabhotla, D. M., Jayaraman, T. V., Asghar, K., \& Das, D. (2016). The optimization of chemical mechanical planarization process-parameters of c-plane gallium-nitride using Taguchi method and grey relational analysis. Materials \& Design, 104, 392-403.

[19] Oh, S., \& Seok, J. (2008). Modeling of chemical-mechanical polishing considering thermal coupling effects. Microelectronic engineering, 85(11), 2191-2201.

[20] Zhao, Y., \& Chang, L. (2002). A micro-contact and wear model for chemicalmechanical polishing of silicon wafers. Wear, 252(3-4), 220-226.

[21] Chen, R., Jiang, R., Lei, H., \& Liang, M. (2013). Material removal mechanism during porous silica cluster impact on crystal silicon substrate studied by molecular dynamics simulation. Applied surface science, 264, 148-156.

[22] Luo, J., \& Dornfeld, D. A. (2001). Material removal mechanism in chemical mechanical polishing: theory and modeling. IEEE transactions on semiconductor manufacturing, 14(2), 112-133.

[23] Jacobs, T. D., Ryan, K. E., Keating, P. L., Grierson, D. S., Lefever, J. A., Turner, K. T., ... \& Carpick, R. W. (2013). The effect of atomic-scale roughness on the adhesion of nanoscale asperities: a combined simulation and experimental investigation. Tribology Letters, 50(1), 81-93.

[24] Pham, V. T., \& Fang, T. H. (2020). Interfacial mechanics and shear deformation of indented germanium on silicon (001) using molecular dynamics. Vacuum, 173, 109184.

[25] Pham, V. T., \& Fang, T. H. (2020). Anisotropic mechanical strength, negative Poisson's ratio and fracture mechanism of borophene with defects. Thin Solid Films, 138197.

[26] Han, X. (2007). Study micromechanism of surface planarization in the polishing technology using numerical simulation method. Applied surface science, 253(14), 62116216. 
[27] Rajendran, A., Takahashi, Y., Koyama, M., Kubo, M., \& Miyamoto, A. (2005). Tightbinding quantum chemical molecular dynamics simulation of mechano-chemical reactions during chemical-mechanical polishing process of $\mathrm{SiO} 2$ surface by $\mathrm{CeO} 2$ particle. Applied Surface Science, 244(1-4), 34-38.

[28] Shah, K., Chiu, P., \& Sinnott, S. B. (2006). Comparison of morphology and mechanical properties of surfactant aggregates at water-silica and water-graphite interfaces from molecular dynamics simulations. Journal of colloid and interface science, 296(1), 342349.

[29] Ranjan, P., Balasubramaniam, R., \& Jain, V. K. (2019). Mechanism of material removal during nanofinishing of aluminium in aqueous $\mathrm{KOH}$ : A reactive molecular dynamics simulation study. Computational Materials Science, 156, 35-46.

[30] Wen, J., Ma, T., Zhang, W., van Duin, A. C., \& Lu, X. (2017). Atomistic mechanisms of Si chemical mechanical polishing in aqueous $\mathrm{H} 2 \mathrm{O} 2$ : ReaxFF reactive molecular dynamics simulations. Computational Materials Science, 131, 230-238.

[31] Shi, J., Chen, J., Fang, L., Sun, K., Sun, J., \& Han, J. (2018). Atomistic scale nanoscratching behavior of monocrystalline $\mathrm{Cu}$ influenced by water film in CMP process. Applied Surface Science, 435, 983-992.

[32] Chagarov, E., \& Adams, J. B. (2003). Molecular dynamics simulations of mechanical deformation of amorphous silicon dioxide during chemical-mechanical polishing. Journal of applied physics, 94(6), 3853-3861.

[33] Chen, J., Shi, J., Chen, Z., Zhang, M., Peng, W., Fang, L., ... \& Han, J. (2019). Mechanical properties and deformation behaviors of surface-modified silicon: a molecular dynamics study. Journal of materials science, 54(4), 3096-3110.

[34] Shi, J., Chen, J., Wei, X., Fang, L., Sun, K., Sun, J., \& Han, J. (2017). Influence of normal load on the three-body abrasion behaviour of monocrystalline silicon with ellipsoidal particle. $R S C$ advances, 7(49), 30929-30940.

[35] Si, L., Guo, D., Luo, J., Lu, X., \& Xie, G. (2011). Abrasive rolling effects on material removal and surface finish in chemical mechanical polishing analyzed by molecular dynamics simulation. Journal of Applied Physics, 109(8), 084335.

[36] Zhang, L., Zhao, H., Ma, Z., Huang, H., Shi, C., \& Zhang, W. (2012). A study on phase transformation of monocrystalline silicon due to ultra-precision polishing by molecular dynamics simulation. AIP Advances, 2(4), 899.

[37] Guo, J., Chen, J., \& Wang, Y. (2020). Temperature effect on mechanical response of cplane monocrystalline gallium nitride in nanoindentation: A molecular dynamics study. Ceramics International.

[38] Plimpton, S. (1995). Fast parallel algorithms for short-range molecular dynamics. Journal of computational physics, 117(1), 1-19. 
[39] Béré, A., \& Serra, A. (2006). On the atomic structures, mobility and interactions of extended defects in GaN: dislocations, tilt and twin boundaries. Philosophical Magazine, 86(15), 2159-2192.

[40] Li, H., Xiang, H., Huang, H., Zeng, Z., \& Peng, X. (2020). Interface structure and deformation mechanisms of AlN/GaN multilayers. Ceramics International.

[41] Kınacı, A., Haskins, J. B., Sevik, C., \& Çağın, T. (2012). Thermal conductivity of BNC nanostructures. Physical Review B, 86(11), 115410.

[42] Cai, K., Yang, L. K., Shi, J., \& Qin, Q. H. (2018). Critical conditions for escape of a high-speed fullerene from a BNC nanobeam after collision. Scientific reports, 8(1), 114.

[43] Wu, C. L., Lin, H. T., Chen, H. A., Lin, S. Y., Shih, M. H., \& Pao, C. W. (2018). Defect formation and modulation during patterning supported graphene sheets using focused ion beams. Materials Today Communications, 17, 60-68.

[44] Stukowski, A. (2009). Visualization and analysis of atomistic simulation data with OVITO-the Open Visualization Tool. Modelling and Simulation in Materials Science and Engineering, 18(1), 015012.

[45] Wang, Y., Tang, S., \& Guo, J. (2020). Molecular dynamics study on deformation behaviour of monocrystalline GaN during nano abrasive machining. Applied Surface Science, 510, 145492.

[46] Pham, V. T., \& Fang, T. H. (2020). Pile-up and heat effect on the mechanical response of SiGe on Si $\left(\begin{array}{lll}0 & 0 & 1\end{array}\right)$ substrate during nanoscratching and nanoindentation using molecular dynamics. Computational Materials Science, 174, 109465.

[47] Agrawal, P. M., Raff, L. M., Bukkapatnam, S., \& Komanduri, R. (2010). Molecular dynamics investigations on polishing of a silicon wafer with a diamond abrasive. Applied Physics A, 100(1), 89-104.

[48] Zhang, L., \& Tanaka, H. (1998). Atomic scale deformation in silicon monocrystals induced by two-body and three-body contact sliding. Tribology international, 31(8), 425-433.

[49] Nguyen, V. T., \& Fang, T. H. (2020). Abrasive mechanisms and interfacial mechanics of amorphous silicon carbide thin films in chemical-mechanical planarization. Journal of Alloys and Compounds, 156100.

[50] Gong, H., Pan, G., Zhou, Y., Shi, X., Zou, C., \& Zhang, S. (2015). Investigation on the surface characterization of $\mathrm{Ga}$-faced $\mathrm{GaN}$ after chemical-mechanical polishing. Applied Surface Science, 338, 85-91.

[51] Shi, X., Zou, C., Pan, G., Gong, H., Xu, L., \& Zhou, Y. (2017). Atomically smooth gallium nitride surface prepared by chemical-mechanical polishing with S2O82--Fe2+ based slurry. Tribology International, 110, 441-450. 
[52] Hanser, D., Tutor, M., Preble, E., Williams, M., Xu, X., Tsvetkov, D., \& Liu, L. (2007). Surface preparation of substrates from bulk GaN crystals. Journal of Crystal Growth, 305(2), 372-376.

[53] Zhong, Z. W., Tian, Y. B., Ng, J. H., \& Ang, Y. J. (2014). Chemical mechanical polishing (CMP) processes for manufacturing optical silicon substrates with shortened polishing time. Materials and Manufacturing Processes, 29(1), 15-19.

[54] Chunyan, Y., Xianhui, Z., \& Wei, P. (2011). Fixed Abrasive Lapping Plate for Lapping Copper Substrates. International Information Institute (Tokyo). Information, 14(12), 3965.

[55] Wang, L., Hu, Z., Yu, Y., \& Xu, X. (2018). Evaluation of Double-Sided Planetary Grinding Using Diamond Wheels for Sapphire Substrates. Crystals, 8(7), 262.

[56] Dong, Y., Lei, H., Liu, W., Wang, T., \& Xu, L. (2018). Preparation of non-spherical silica composite abrasives by lanthanum ion-induced effect and its chemical-mechanical polishing properties on sapphire substrates. Journal of materials science, 53(15), 1073210742 .

[57] Si, L., Guo, D., Luo, J., Lu, X., \& Xie, G. (2011). Abrasive rolling effects on material removal and surface finish in chemical mechanical polishing analyzed by molecular dynamics simulation. Journal of Applied Physics, 109(8), 084335.

[58] Nguyen, V. T., \& Fang, T. H. (2019). Material removal and interactions between an abrasive and a $\mathrm{SiC}$ substrate: A molecular dynamics simulation study. Ceramics International. 


\section{Acknowledgments}

The authors acknowledge the support by the Ministry of Science and Technology, Taiwan under grant numbers MOST 109-2622-E-992-011-CC3, and MOST 109-2221-E-992-009-MY3.

\section{Author information}

\section{Affiliations}

Department of Mechanical Engineering, National Kaohsiung University of Science and Technology, Kaohsiung, 807, Taiwan

Van-Thuc Nguyen \& Te-Hua Fang

Institute of Research and Development, Duy Tan University, Danang, 550000, Vietnam Van-Thuc Nguyen

\section{Contributions}

Van-Thuc Nguyen: Formal analysis, Investigation, Software, Writing - original draft, Visualization Conceptualization, Writing - review \& editing. Te-Hua Fang: Data curation, Funding acquisition, Methodology, Project administration, Resources, Validation.

\section{Corresponding author}

Correspondence to Te-Hua Fang.

\section{Ethics declarations}

\section{Competing interests}

The authors declare no competing interests.

\section{Additional information}

\section{Publisher's note}

Springer Nature remains neutral with regard to jurisdictional claims in published maps and institutional affiliations. 


\section{Figure captions}

Fig.1. Simulation model.

Fig. 2. The radial distribution functions of GaN substrate.

Fig. 3. Forces at different polishing depths at $1.0 \AA$ ps in sliding motion: (a) $0.5 \AA$, (b) $1.0 \AA$, (c) $2.0 \AA$, (d) $3.0 \AA$, (e) $5.0 \AA$, and (f) $10 \AA$.

Fig. 4. Structure change and surface morphology of the workpiece at different polishing depths at $1.0 \AA /$ ps in sliding motion: (a) $0.5 \AA$, (b) $1.0 \AA$, (c) $2.0 \AA$, (d) $3.0 \AA$, (e) $5.0 \AA$, and (f) $10 \AA$.

Fig. 5. Von Mises stress distribution of the workpiece at different polishing depths at $1.0 \AA / \mathrm{ps}$ in sliding motion: (a) $0.5 \AA$, (b) $1.0 \AA$, (c) $2.0 \AA$, (d) $3.0 \AA$, (e) $5.0 \AA$, and (f) $10 \AA$.

Fig. 6. Temperature distribution of the workpiece at different polishing depths at $1.0 \AA / \mathrm{ps}$ in sliding motion: (a) $0.5 \AA$, (b) $1.0 \AA$, (c) $2.0 \AA$, (d) $3.0 \AA$, (e) $5.0 \AA$, and (f) $10 \AA$.

Fig. 7. Maximum shear stress and dislocation mobility at $10 \AA$ depth and $1.0 \AA$ ps: (a) maximum shear stress, (b) dislocation mobility.

Fig. 8. Total dislocation length during the sliding process at $\mathrm{t} 10 \AA$ depth and $1.0 \AA \mathrm{s} / \mathrm{ps}$.

Fig. 9. Kinetic energies at different velocities at $5.0 \AA$ depth in sliding motion.

Fig. 10. Forces at different polishing depths when the abrasive rotates at $50 \mathrm{rad} / \mathrm{ns}$ and moves at $1.0 \AA /$ ps in rolling motion: (a) $0.5 \AA$, (b) $1.0 \AA$, (c) $2.0 \AA$, (d) $3.0 \AA$, (e) $5.0 \AA$, and (f) $10 \AA$.

Fig. 11. Structure change of the workpiece at different polishing depths when the abrasive rotates at $50 \mathrm{rad} / \mathrm{ns}$ and moves at $1.0 \AA$ /ps in rolling motion: (a) $0.5 \AA$, (b) $1.0 \AA$, (c) $2.0 \AA$, (d) $3.0 \AA$, (e) $5.0 \AA$, and (f) $10 \AA$.

Fig. 12. Deformation and wear mechanisms of sliding and rolling motions.

Fig. 13. Von Mises stress distribution of the workpiece at different polishing depths when the abrasive rotates at $50 \mathrm{rad} / \mathrm{ns}$ and moves at $1.0 \AA / \mathrm{ps}$ in rolling motion: (a) $0.5 \AA$, (b) $1.0 \AA$, (c) 2.0 $\AA$, (d) $3.0 \AA$, (e) $5.0 \AA$, and (f) $10 \AA$.

Fig. 14. Hydrostatic stress distribution of the workpiece at different polishing depths when the abrasive rotates at $50 \mathrm{rad} / \mathrm{ns}$ and moves at $1.0 \AA / \mathrm{ps}$ in rolling motion: (a) $0.5 \AA$, (b) $1.0 \AA$, (c) 2.0 $\AA$, (d) $3.0 \AA$, (e) $5.0 \AA$, (f) $10 \AA$, and (f1) surface morphology at $10 \AA$.

Fig. 15. Temperature distribution of the workpiece at different polishing depths when the abrasive rotates at $50 \mathrm{rad} / \mathrm{ns}$ and moves at $1.0 \AA / \mathrm{ps}$ in rolling motion: (a) $0.5 \AA$, (b) $1.0 \AA$, (c) $2.0 \AA$, (d) 5.0 $\AA$, and (e) $10 \AA$. 
Fig. 16. Maximum shear stress and dislocation mobilities at $10 \AA$ depths, rolling at $50 \mathrm{rad} / \mathrm{ns}$ and moving at $1.0 \AA$ /ps: (a) maximum shear stress, (b) dislocation mobility.

Fig. 17. Total dislocation length during the rolling process at $10 \AA$ depths, rolling at $50 \mathrm{rad} / \mathrm{ns}$ and moving at $1.0 \AA / \mathrm{ps}$.

Fig. 18. Total kinetic energies and kinetic energy distribution at different velocities at $5.0 \AA$ depth, moving at $1.0 \AA / \mathrm{ps}$ in rolling motion.

Fig. 19. Total forces of different abrasive sizes at $1.0 \AA$ A/ps and $5.0 \AA$ depth.

Fig. 20. Surface morphology and von Mises stress distribution of different abrasive sizes sliding at $1.0 \AA$ ps and $5.0 \AA$ depth: (a) $30 \AA$, (b) $40 \AA$, and (c) $50 \AA$.

Fig. 21. Surface morphology and von Mises stress distribution of different abrasive sizes rolling at $50 \mathrm{rad} / \mathrm{ns}$, moving at $1.0 \AA / \mathrm{ps}$ and $5.0 \AA$ depth: (a) $30 \AA$, (b) $40 \AA$, and (c) $50 \AA$.

Fig. 22. Total forces of different polishing direction and face at $1.0 \AA$ /ps and $5.0 \AA$ depth: (a) sliding motions, and (b) rolling motions.

Fig. 23. Surface morphology and von Mises stress distribution of different sliding directions and faces, sliding at $1.0 \AA$ A/ps and $5.0 \AA$ depth: (a) [1-100] direction/Ga-face, (b) [11-20] direction/Gface, and (c) [11-20] direction/N-face.

Fig. 24. Surface morphology and von Mises stress distribution of different rolling directions and faces, rolling at $50 \mathrm{rad} / \mathrm{ns}$, moving at $1.0 \AA$ A $/ \mathrm{ps}$ and $5.0 \AA$ Aepth: (a) [1-100] direction/G-face, (b) [11-20] direction/G-face, and (c) [11-20] direction/N-face. 


\section{Tables}

Table 1. Number of atoms removed at different depths and speeds in sliding motion.

\begin{tabular}{cllllll}
\hline Velocity $(\AA / \mathbf{A} / \mathbf{p s})$ & $\mathbf{0 . 5} \mathbf{\AA}$ depth & $\mathbf{1} \mathbf{A}$ depth & $\mathbf{2} \AA$ depth & $\mathbf{3} \AA$ depth & $\mathbf{5} \AA$ depth & $\mathbf{1 0} \AA$ depth \\
\hline 0.5 & 1 & 1 & 9 & 1 & 101 & 1754 \\
\hline 1.0 & 0 & 1 & 7 & 0 & 191 & 1613 \\
\hline 2.0 & 1 & 1 & 10 & 3 & 532 & 1592 \\
\hline Average & 0.7 & 1 & 8.7 & 1.3 & 274.7 & 1653 \\
\hline
\end{tabular}


Table 2. Number of atoms removed at different depths and speeds in rolling motion.

\begin{tabular}{ccccccc}
\hline Velocity (rad/ns) & $\mathbf{0 . 5} \AA$ depth & $\mathbf{1 . 0} \AA$ depth & $\mathbf{2 . 0} \AA$ depth & $\mathbf{3 . 0} \AA$ 㪀th & $\mathbf{5 . 0} \AA$ depth & $\mathbf{1 0} \AA$ depth \\
\hline 50 & 37 & 83 & 204 & 409 & 672 & 846 \\
\hline 100 & 61 & 93 & 189 & 236 & 574 & 1080 \\
\hline 200 & 94 & 170 & 291 & 456 & 674 & 1045 \\
\hline Average & 64 & 115.3 & 228 & 367 & 640 & 990.3 \\
\hline
\end{tabular}


Table 3. Comparison of the ratio of number of removed atoms between the rolling and the sliding motions.

\begin{tabular}{llll}
\hline Methods & No. rolling /No. sliding & Materials of abrasive/wafer & References \\
\hline Experimental & 0.11 & Diamond/Si & Zhong et al. [53] \\
\hline Experimental & $0.14-0.2$ & $\mathrm{Al}_{2} \mathrm{O}_{3} / \mathrm{Cu}$ & Chunyan et al. [54] \\
\hline Experimental & $0.3-0.4$ & Diamond $/ \mathrm{Al}_{2} \mathrm{O}_{3}$ & Wang et al. [55] \\
\hline Experimental & 0.75 & $\mathrm{SiO}_{2} / \mathrm{Al}_{2} \mathrm{O}_{3}$ & Dong et al. [56] \\
\hline Simulation & $0.71-0.86$ & $\mathrm{SiO}_{2} / \mathrm{Si}$ & Si et al. [57] \\
\hline Simulation & $0.56-2.0$ & Diamond/SiC & Nguyen et al. [58] \\
\hline Simulation & $1.2-6.65$ & Diamond/GaN & This research \\
\hline
\end{tabular}


Figures

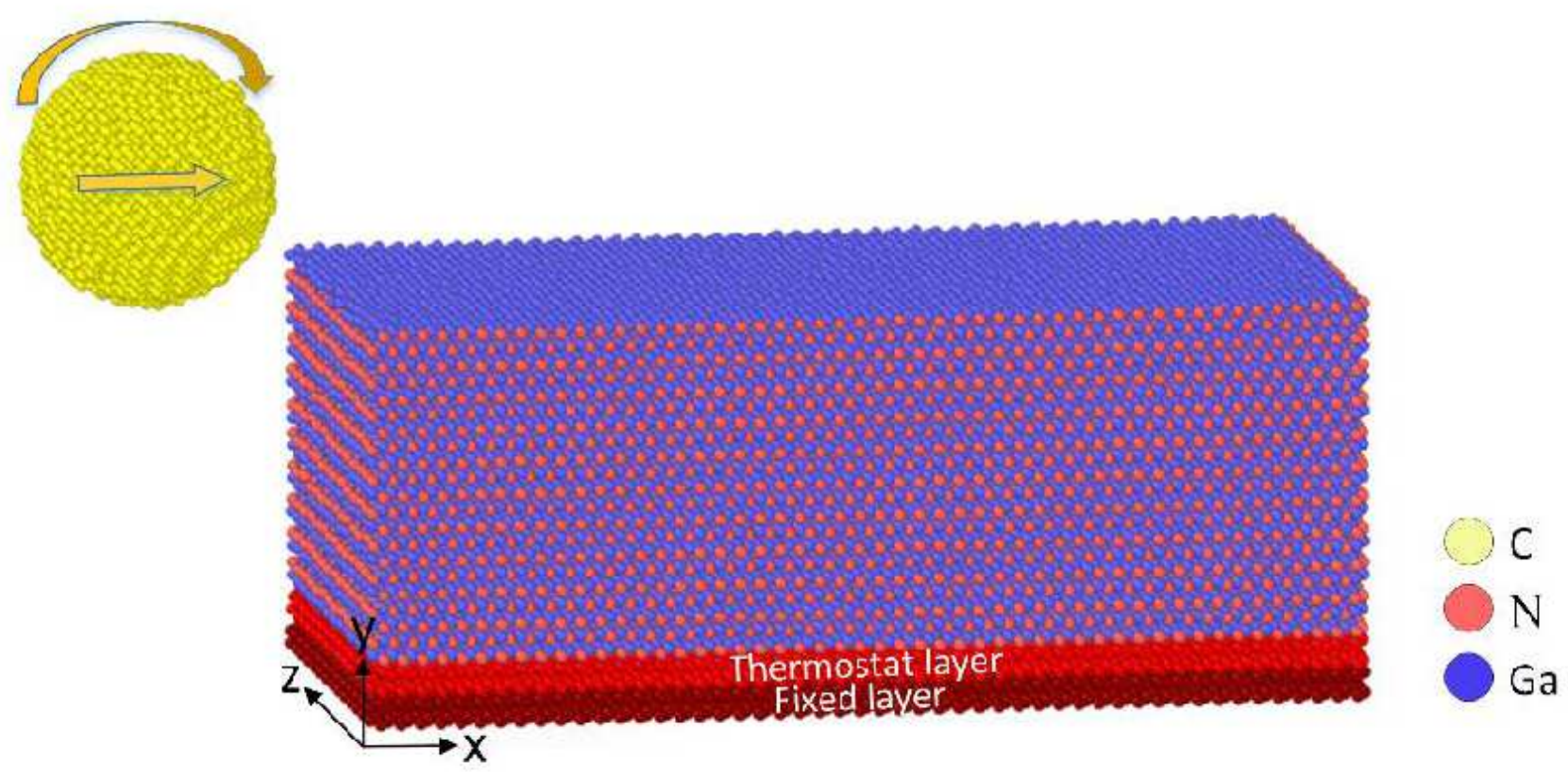

Figure 1

Simulation model. 


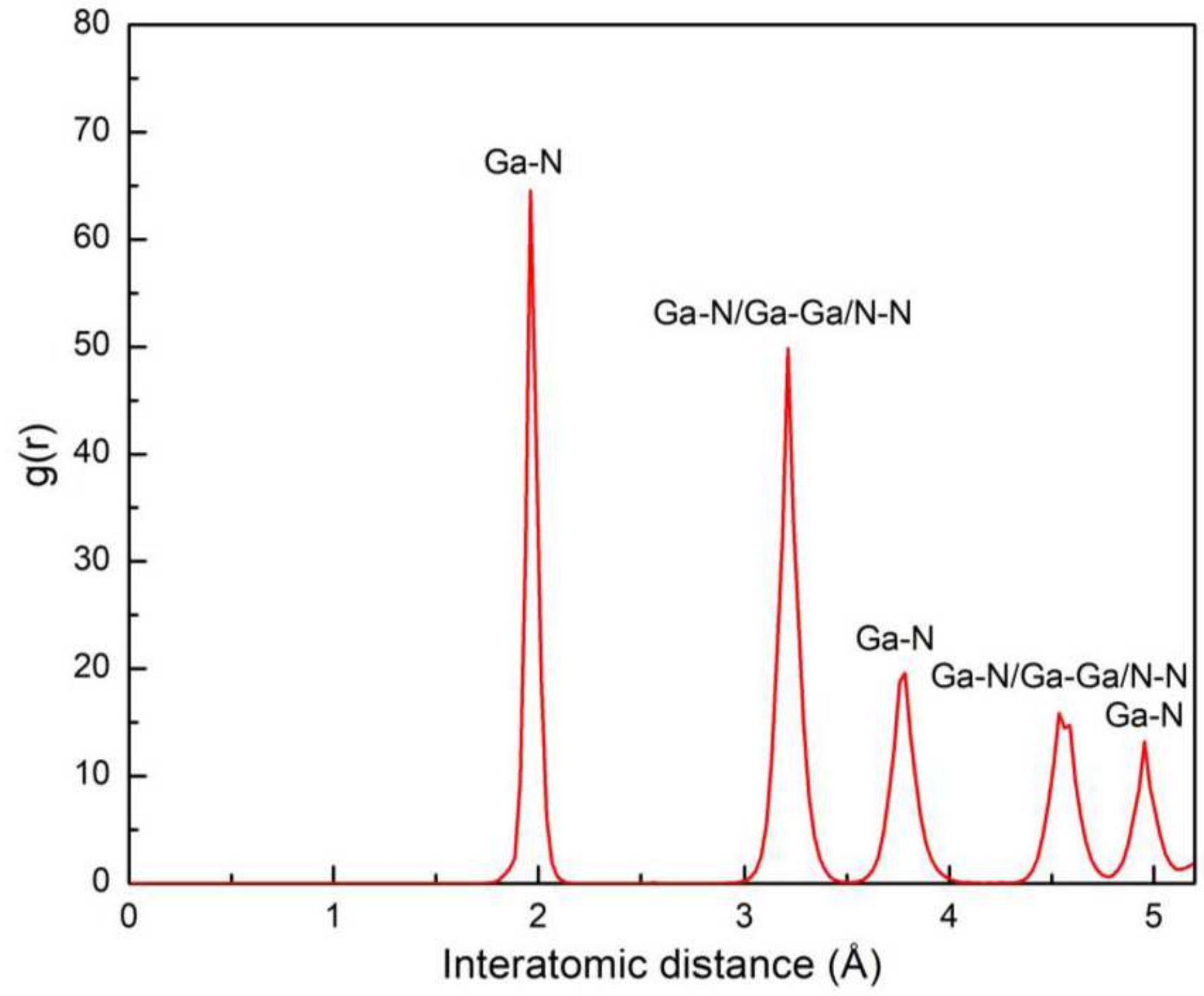

Figure 2

The radial distribution functions of GaN substrate. 


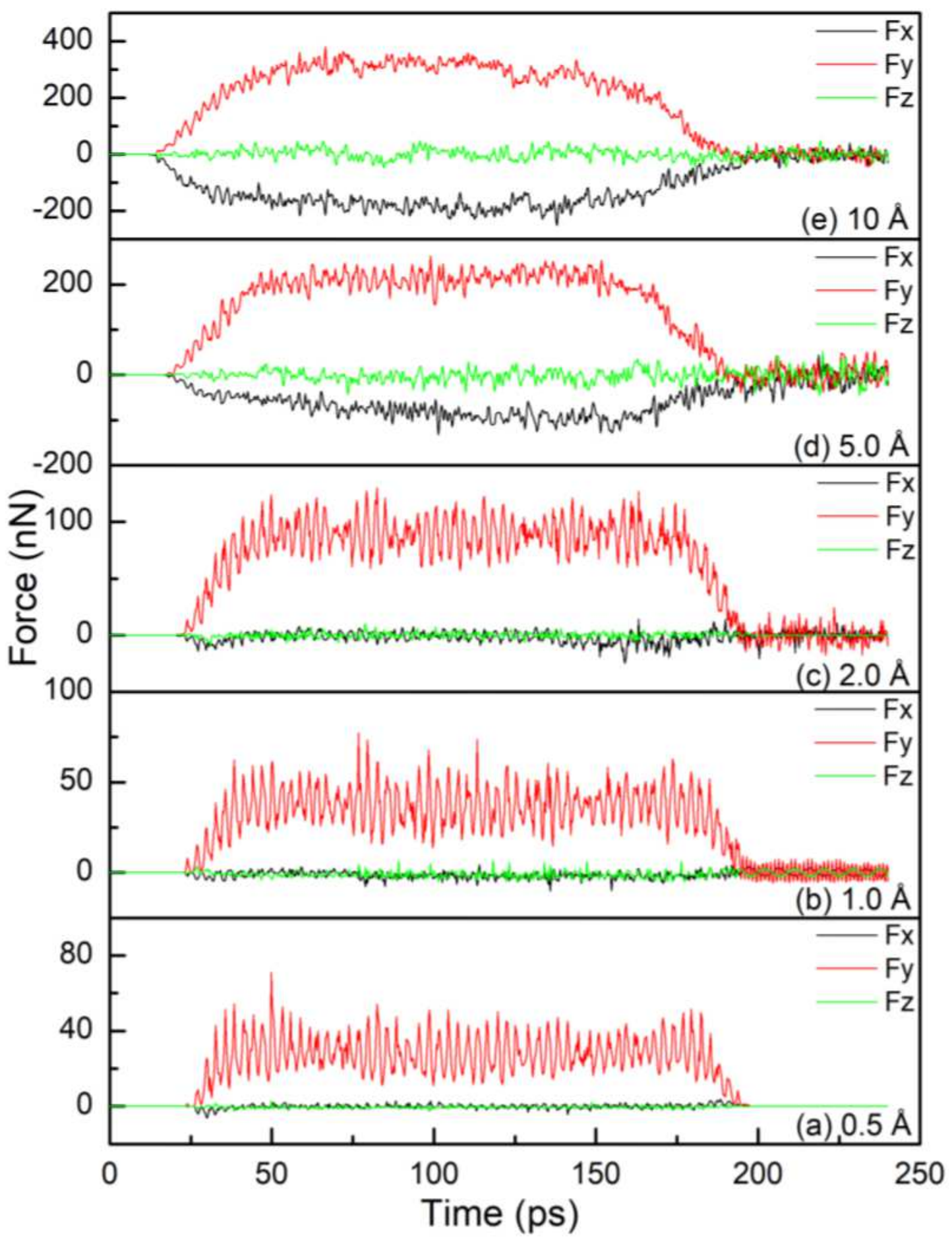

Figure 3

Forces at different polishing depths at $1.0 \AA$ ps in sliding motion: (a) $0.5 \AA$, (b) $1.0 \AA$, (c) $2.0 \AA$, (d) $3.0 \AA$, (e) $5.0 \AA$, and (f) $10 \AA$. 


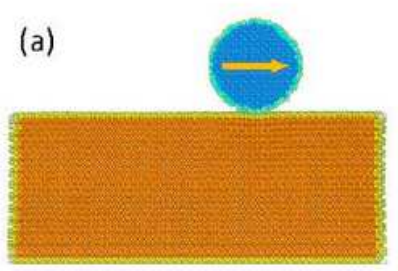

(b)
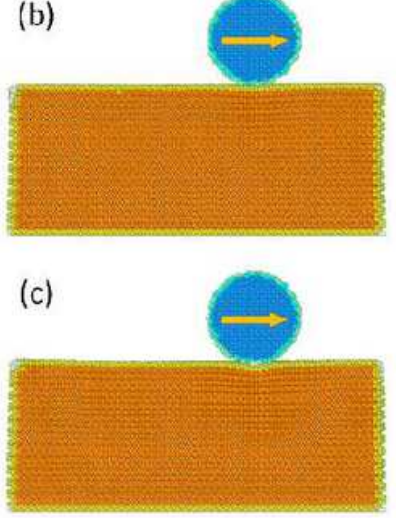
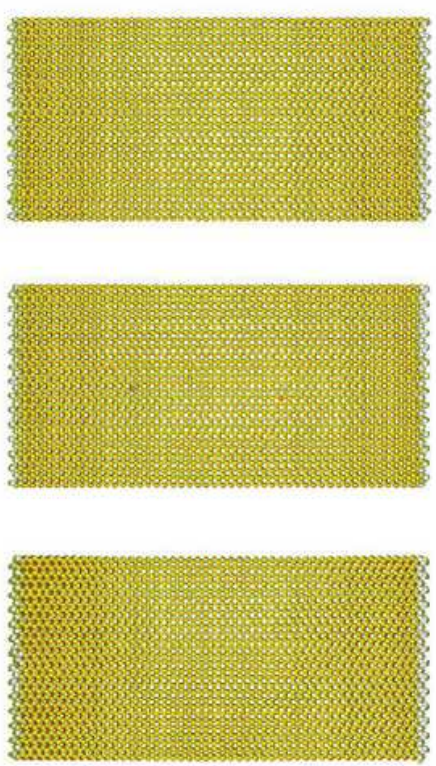

(d)
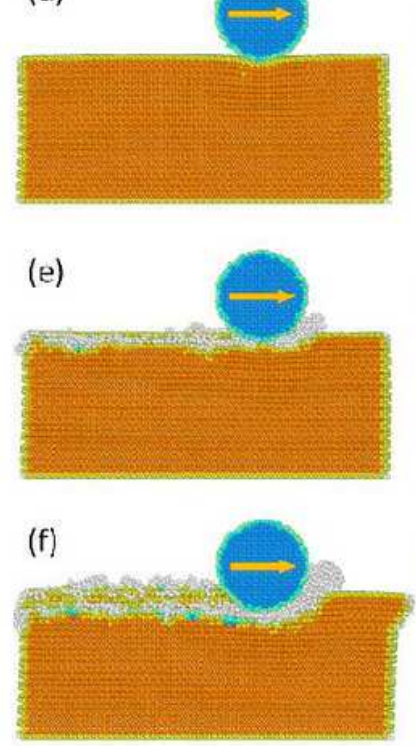

Amorphous

Cubic diamond

Cubic diamond (1st neighbor)

Cubic diamond (2nd neighbor)
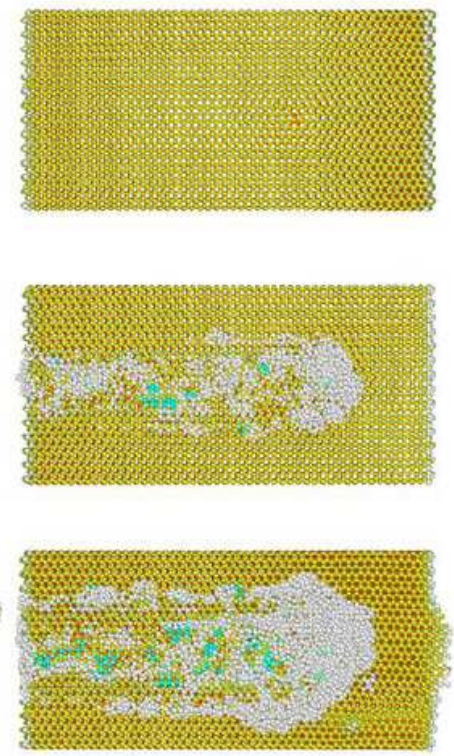

- Hexagonal diamond

Hexagonal diamonc (1st neighbor)

Hexagonal diamonc (2nd neighbor)

\section{Figure 4}

Structure change and surface morphology of the workpiece at different polishing depths at $1.0 \AA \mathrm{A} / \mathrm{ps}$ in sliding motion: (a) $0.5 \AA$, (b) $1.0 \AA$, (c) $2.0 \AA$, (d) $3.0 \AA$, (e) $5.0 \AA$, and (f) $10 \AA$.

\section{$0 \square 5 \mathrm{GPa}$}

(a)

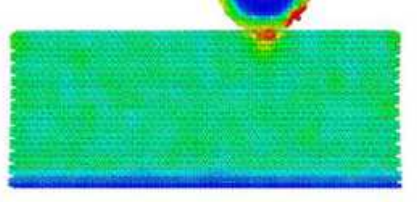

(b)

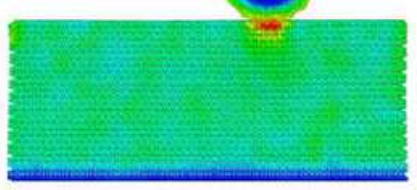

(c)

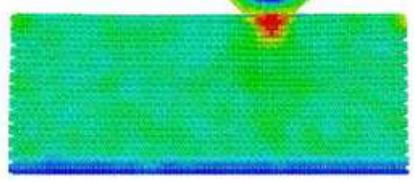

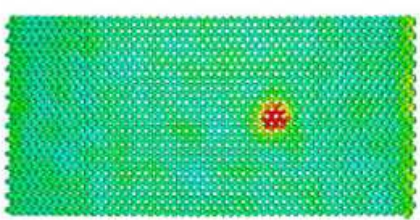
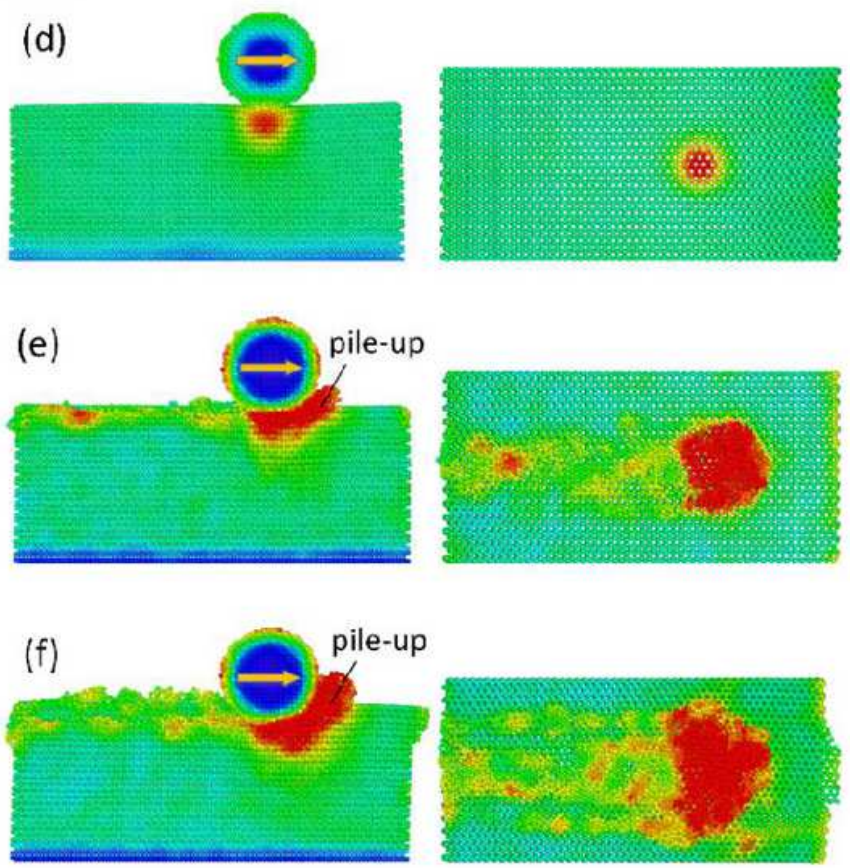


\section{Figure 5}

Von Mises stress distribution of the workpiece at different polishing depths at $1.0 \AA \mathrm{p} / \mathrm{ps}$ in sliding motion: (a) $0.5 \AA$, (b) $1.0 \AA$, (c) $2.0 \AA$, (d) $3.0 \AA$, (e) $5.0 \AA$, and (f) $10 \AA$.

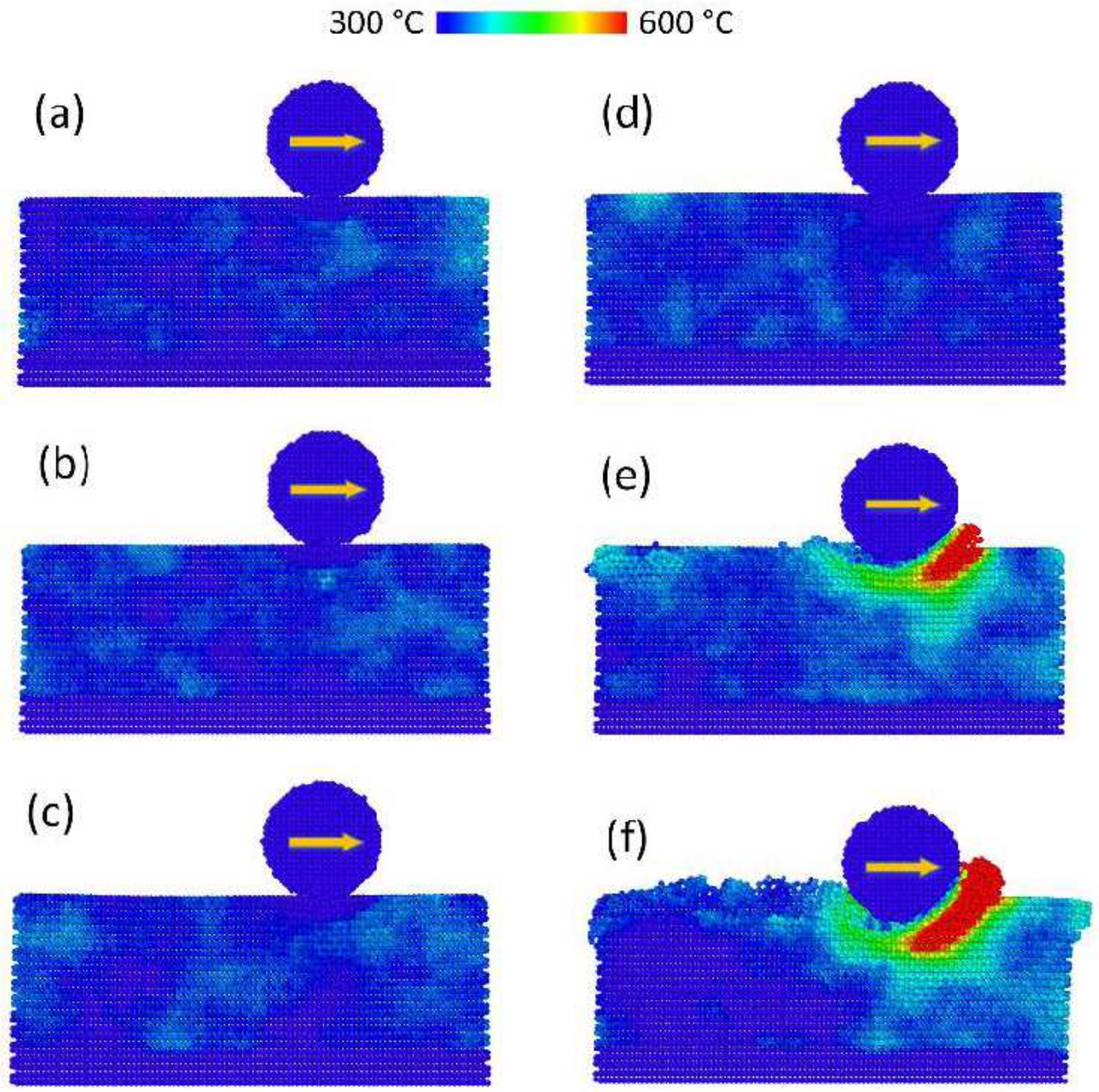

Figure 6

Temperature distribution of the workpiece at different polishing depths at $1.0 \AA / p s$ in sliding motion: (a) $0.5 \AA$, (b) $1.0 \AA$, (c) $2.0 \AA$, (d) $3.0 \AA$, (e) $5.0 \AA$, and (f) $10 \AA$. 
(a)
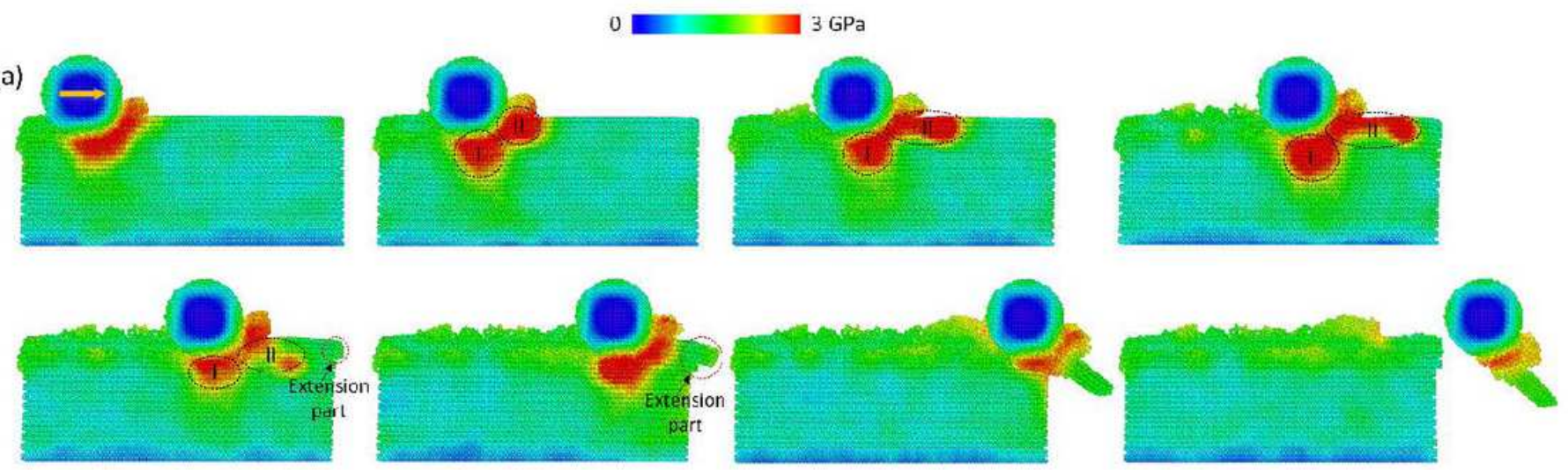

(b)
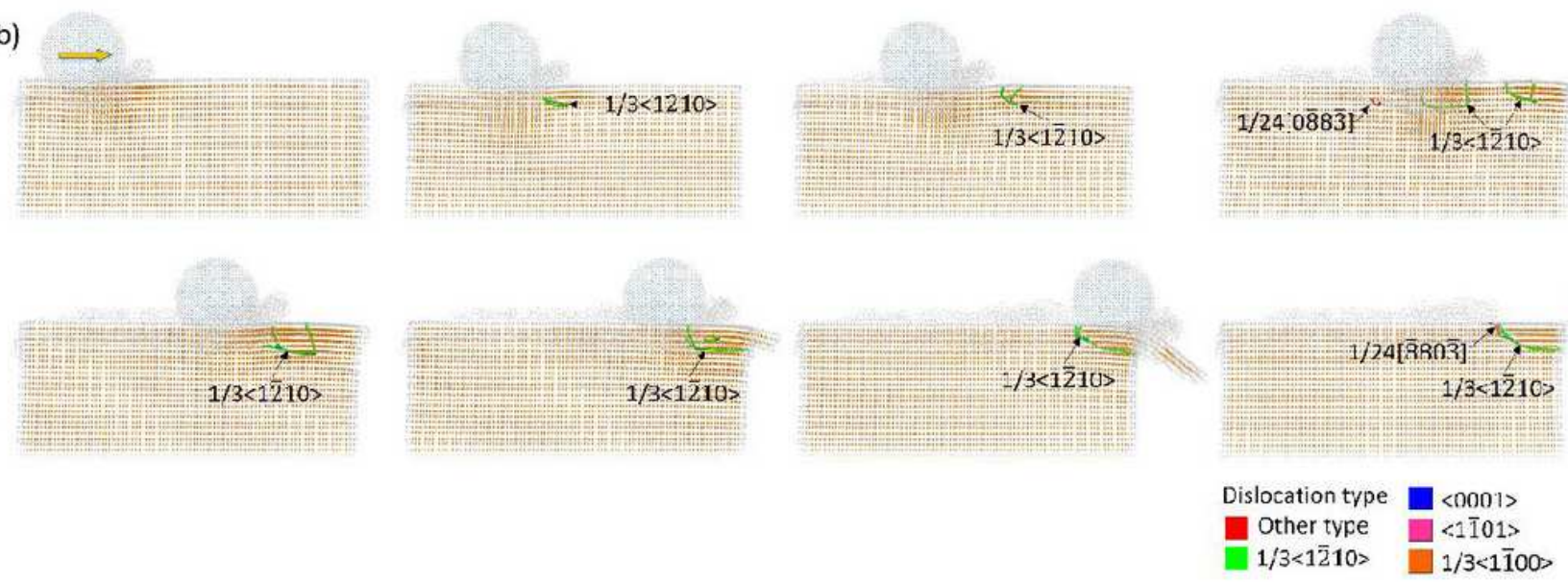

\section{Figure 7}

Maximum shear stress and dislocation mobility at $10 \AA$ depth and $1.0 \AA$ ps: (a) maximum shear stress, (b) dislocation mobility. 


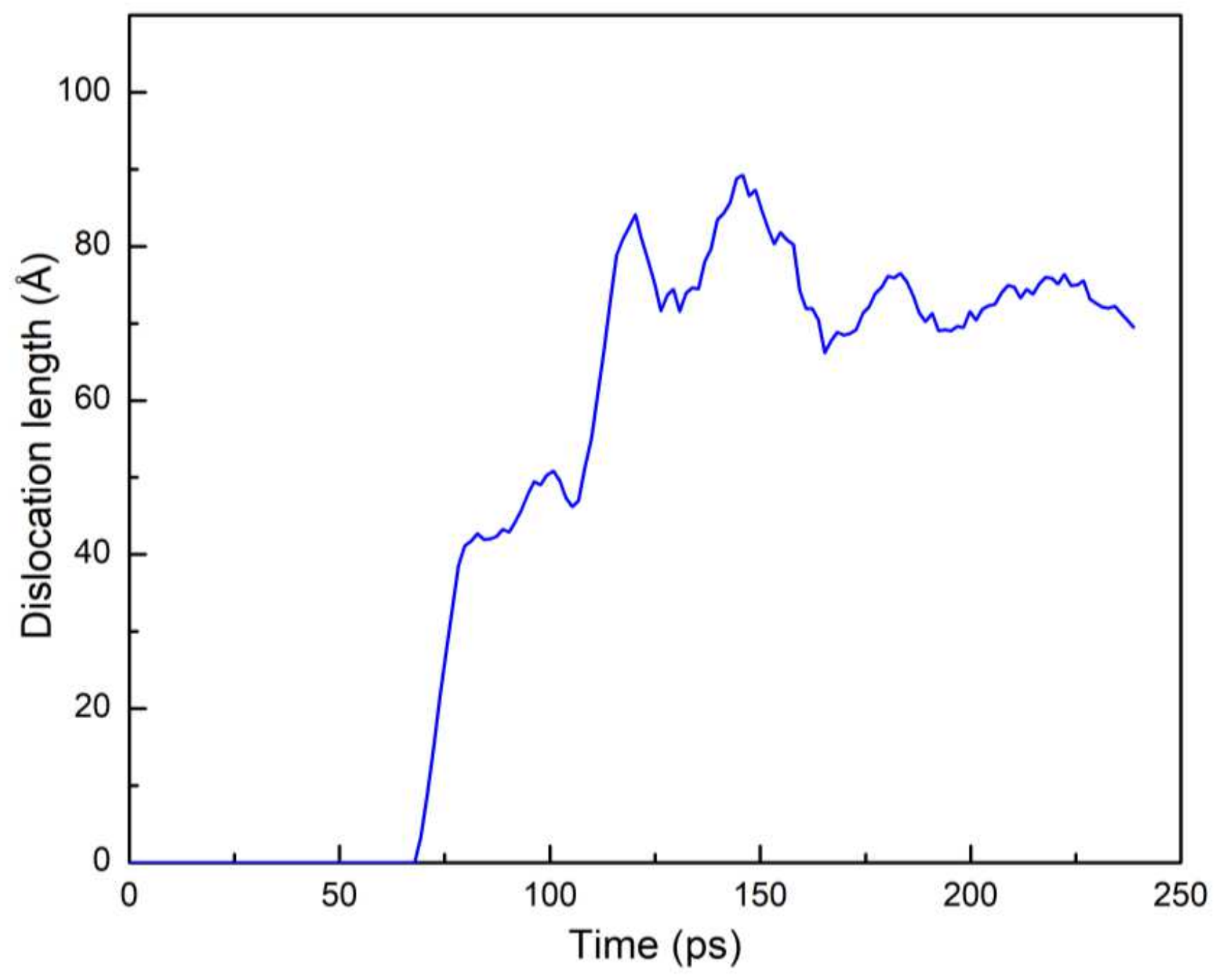

Figure 8

Total dislocation length during the sliding process at $\mathrm{t} 10 \AA$ depth and $1.0 \AA \mathrm{A} / \mathrm{ps}$. 


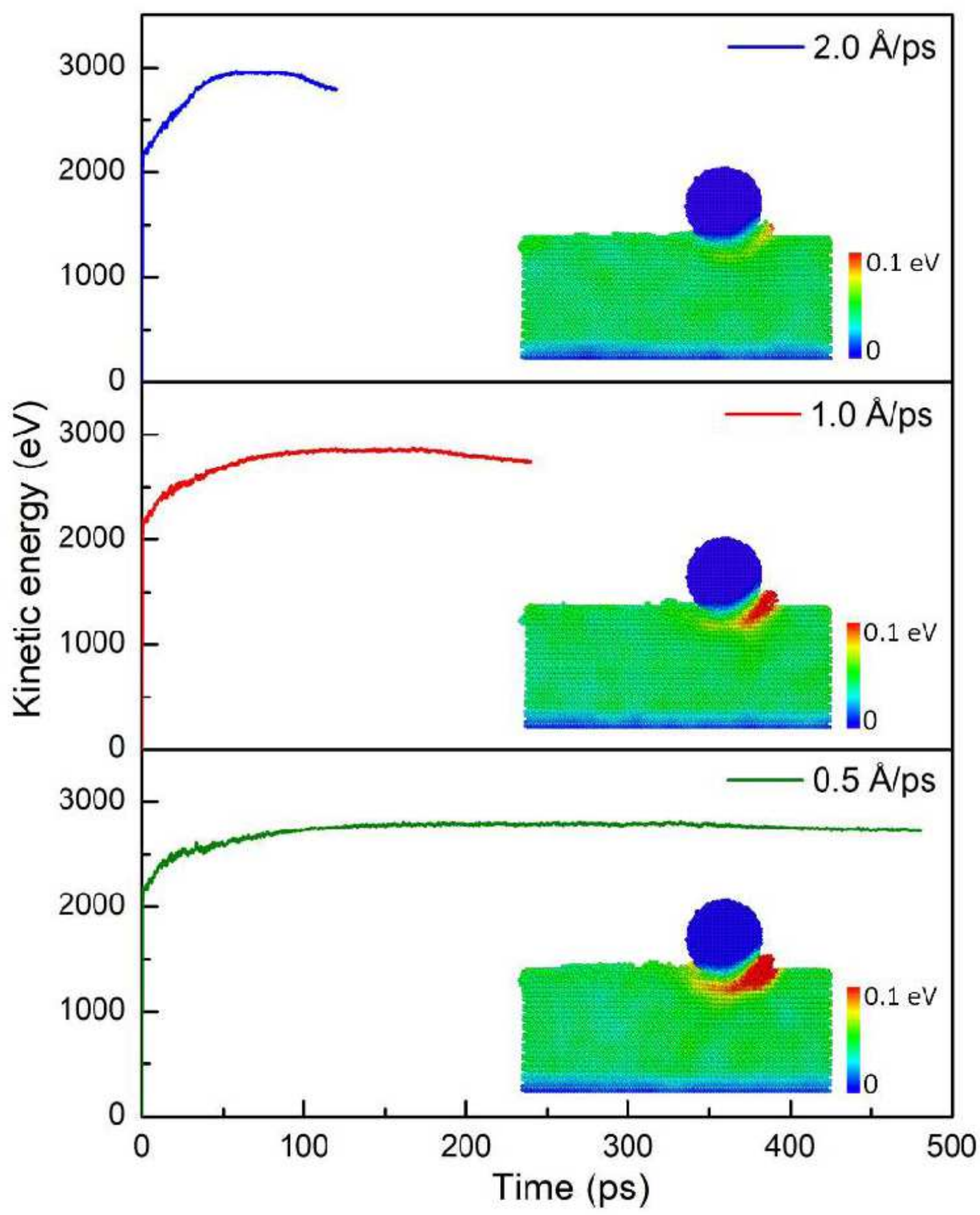

Figure 9

Kinetic energies at different velocities at $5.0 \AA$ depth in sliding motion. 


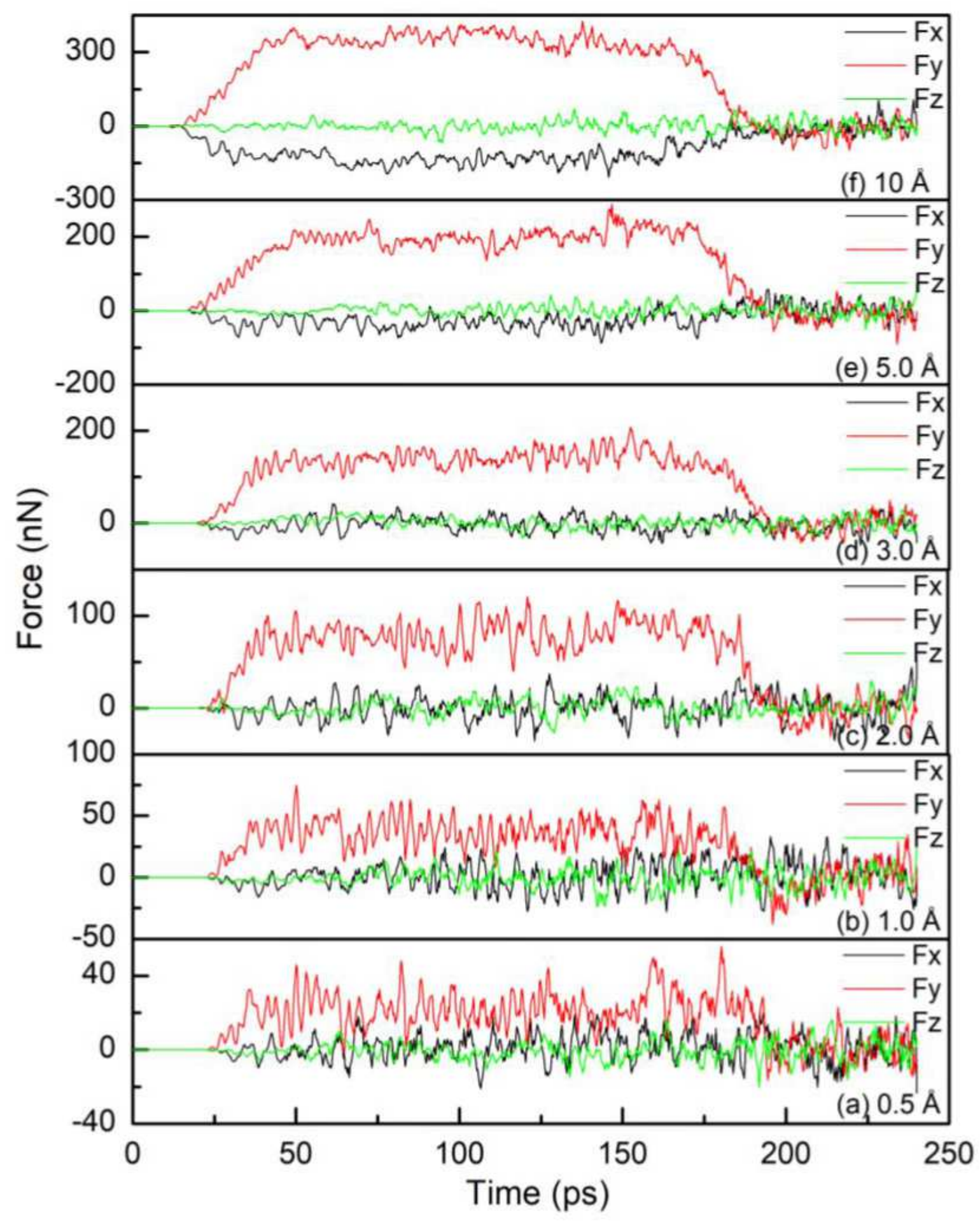

Figure 10

Forces at different polishing depths when the abrasive rotates at $50 \mathrm{rad} / \mathrm{ns}$ and moves at $1.0 \AA \mathrm{ps}$ in rolling motion: (a) $0.5 \AA$, (b) $1.0 \AA$, (c) $2.0 \AA$, (d) $3.0 \AA$, (e) $5.0 \AA$, and (f) $10 \AA$. 

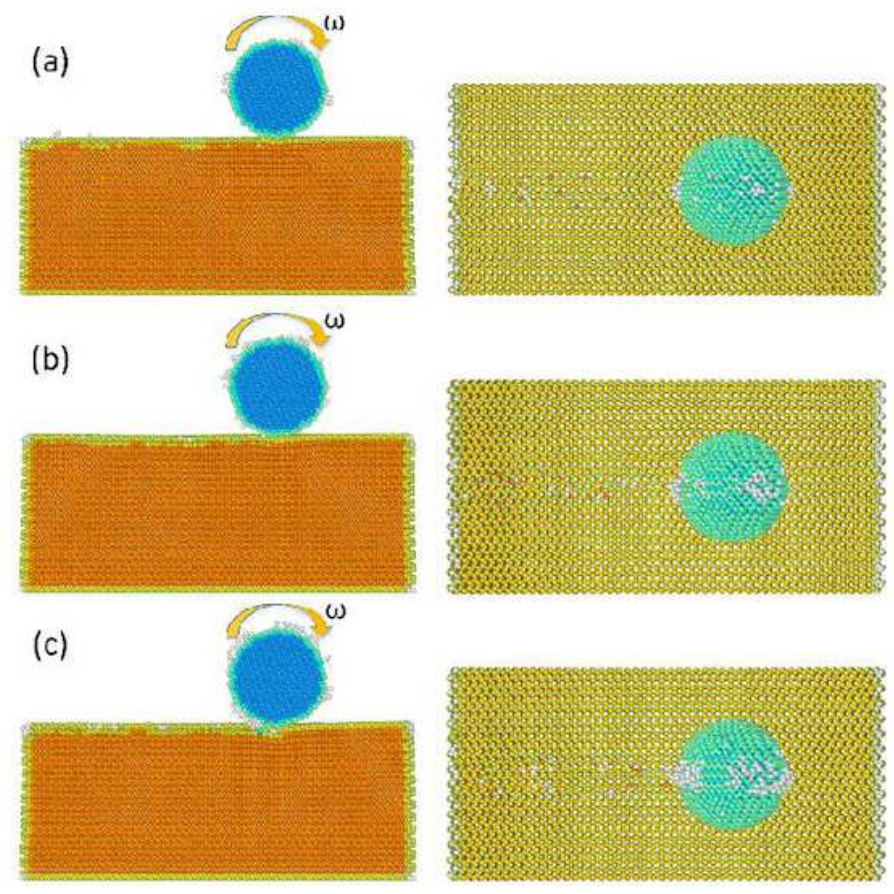
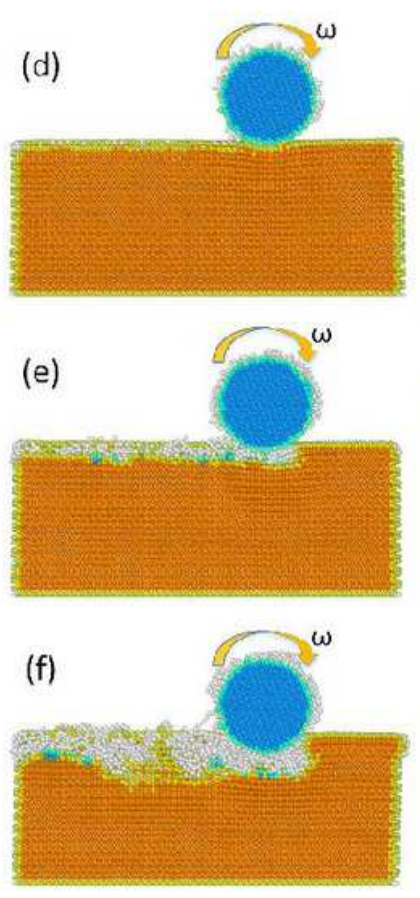
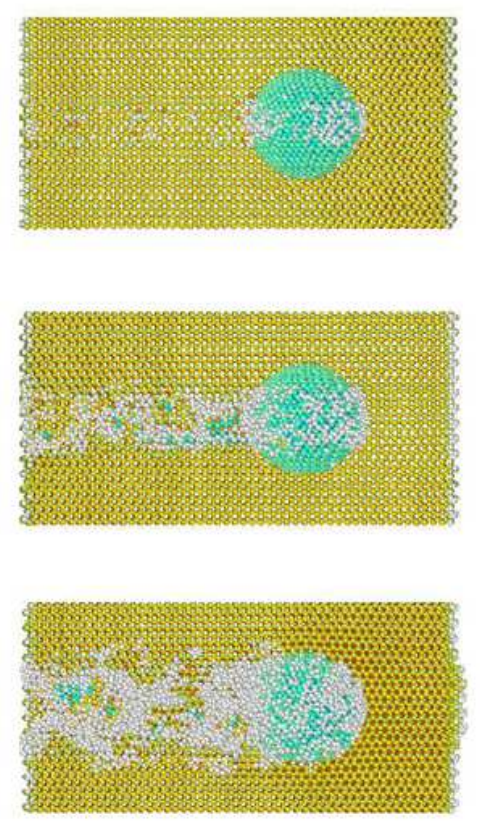

\section{Figure 11}

Structure change of the workpiece at different polishing depths when the abrasive rotates at $50 \mathrm{rad} / \mathrm{ns}$ and moves at $1.0 \AA$ ps in rolling motion: (a) $0.5 \AA$, (b) $1.0 \AA$, (c) $2.0 \AA$, (d) $3.0 \AA$, (e) $5.0 \AA$, and (f) $10 \AA$. 

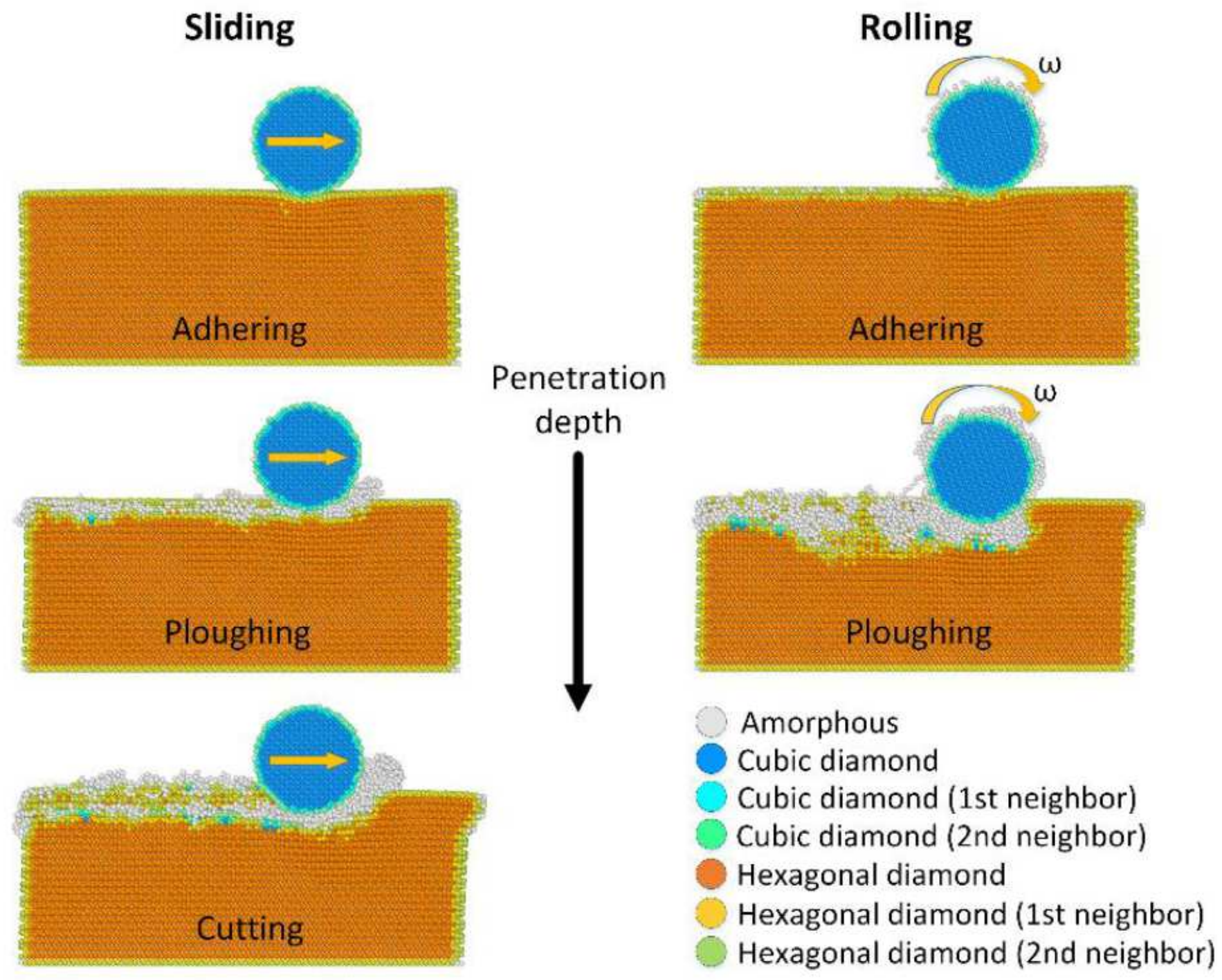

Figure 12

Deformation and wear mechanisms of sliding and rolling motions. 

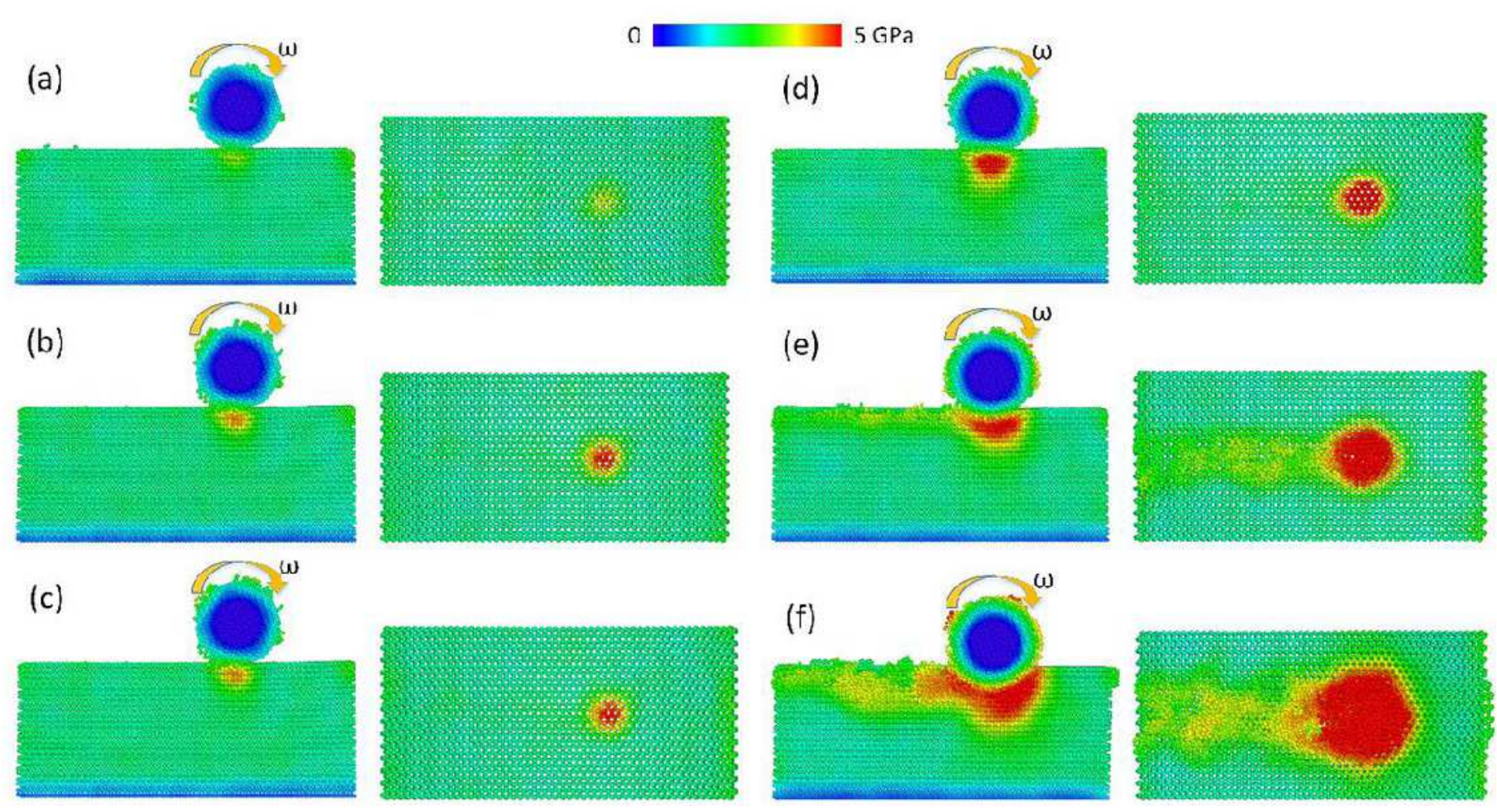

\section{Figure 13}

Von Mises stress distribution of the workpiece at different polishing depths when the abrasive rotates at $50 \mathrm{rad} / \mathrm{ns}$ and moves at $1.0 \AA$ /ps in rolling motion: (a) $0.5 \AA$, (b) $1.0 \AA$, (c) $2.0 \AA$, (d) $3.0 \AA$, (e) $5.0 \AA$, and (f) $10 \AA$. 

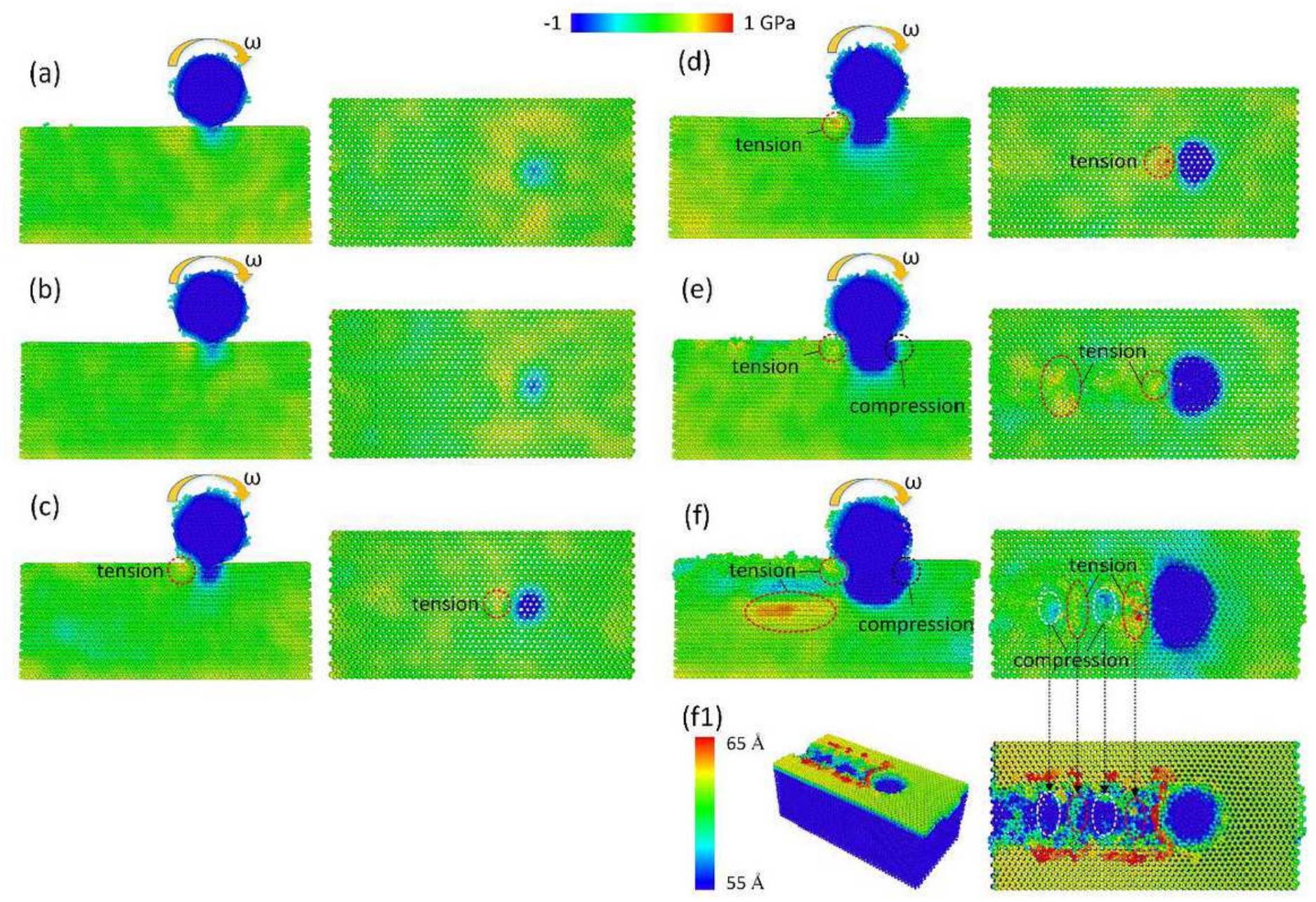

\section{Figure 14}

Hydrostatic stress distribution of the workpiece at different polishing depths when the abrasive rotates at $50 \mathrm{rad} / \mathrm{ns}$ and moves at $1.0 \AA$ /ps in rolling motion: (a) $0.5 \AA$, (b) $1.0 \AA$, (c) $2.0 \AA$, (d) $3.0 \AA$, (e) $5.0 \AA$, (f) 10 $\AA$, and (f1) surface morphology at $10 \AA$. 

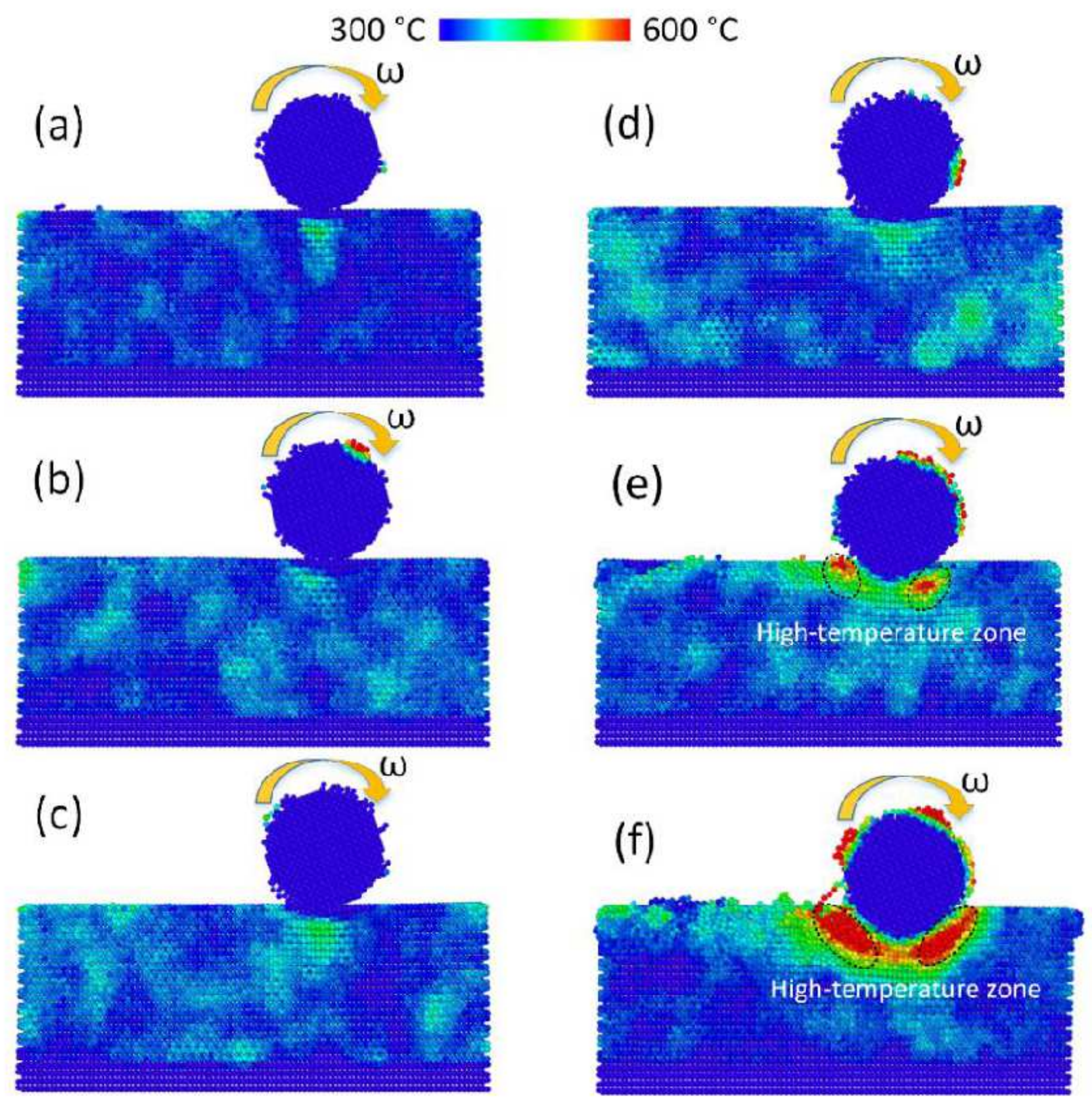

Figure 15

Temperature distribution of the workpiece at different polishing depths when the abrasive rotates at 50 $\mathrm{rad} / \mathrm{ns}$ and moves at $1.0 \AA$ /ps in rolling motion: (a) $0.5 \AA$, (b) $1.0 \AA$, (c) $2.0 \AA$, (d) $5.0 \AA$, and (e) $10 \AA$. 
(a)
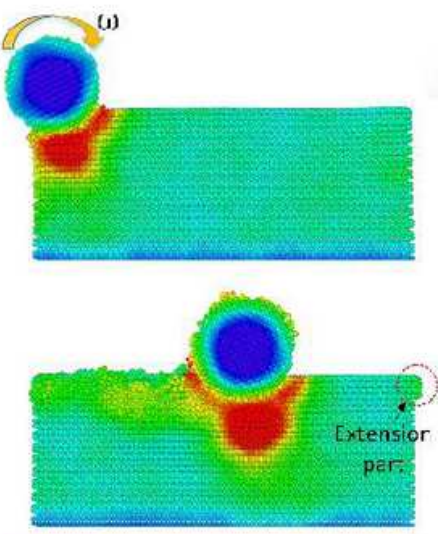

(b)
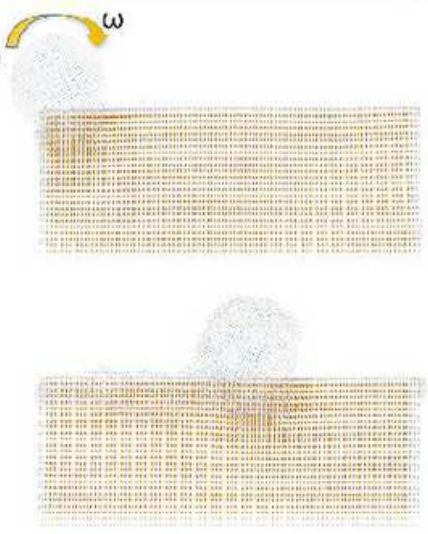
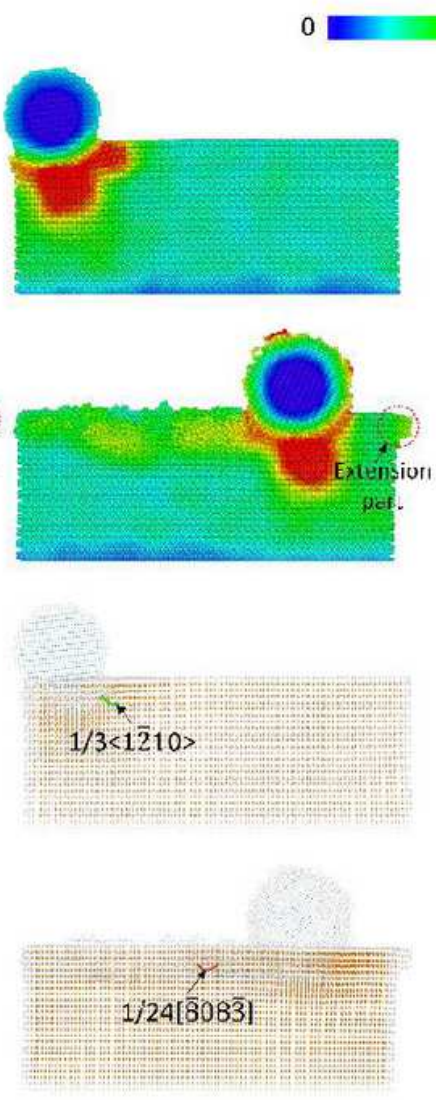

$3 \mathrm{GPa}$
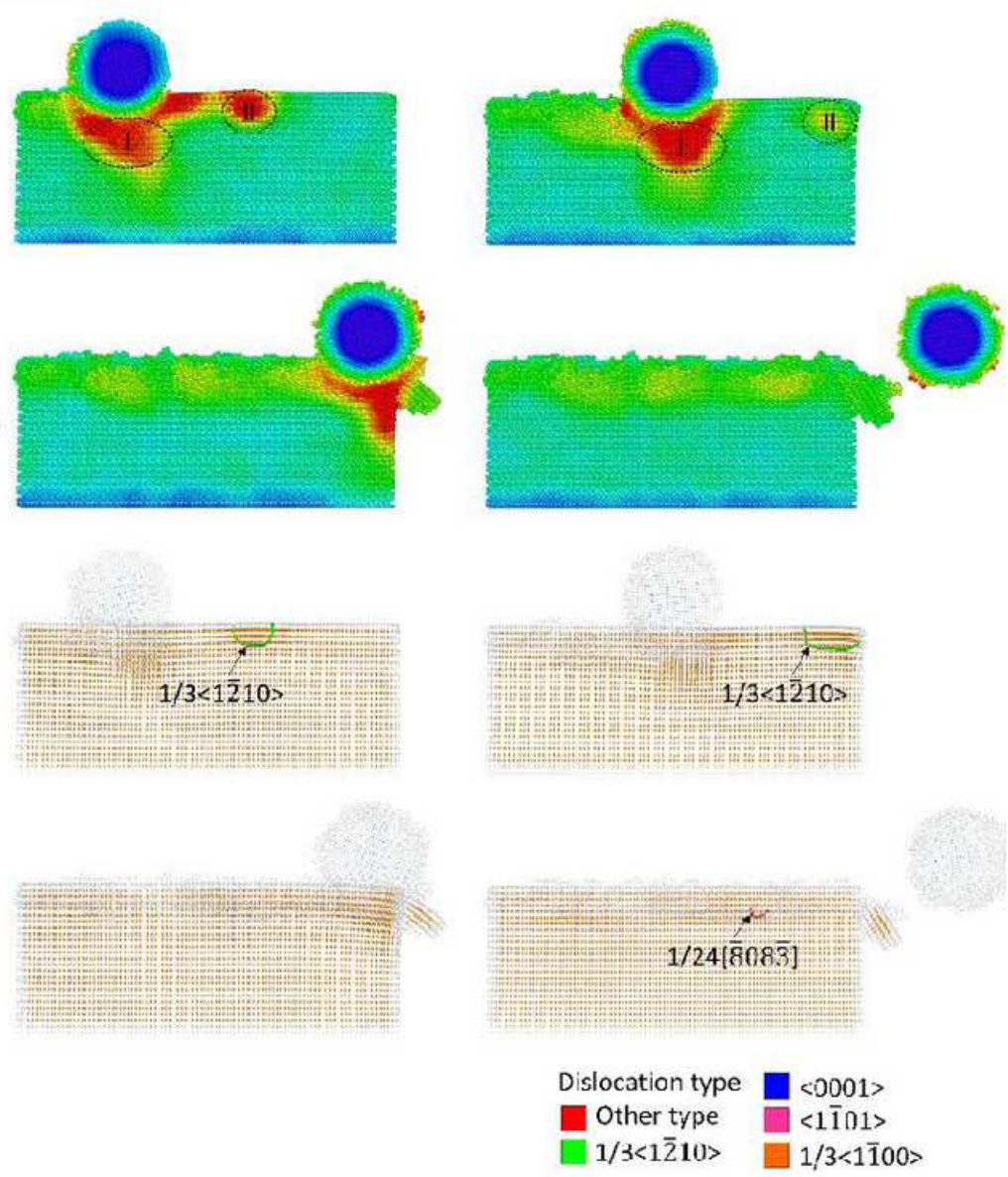

\section{Figure 16}

Maximum shear stress and dislocation mobilities at $10 \AA$ depths, rolling at $50 \mathrm{rad} / \mathrm{ns}$ and moving at 1.0 $\AA / p s:$ (a) maximum shear stress, (b) dislocation mobility. 


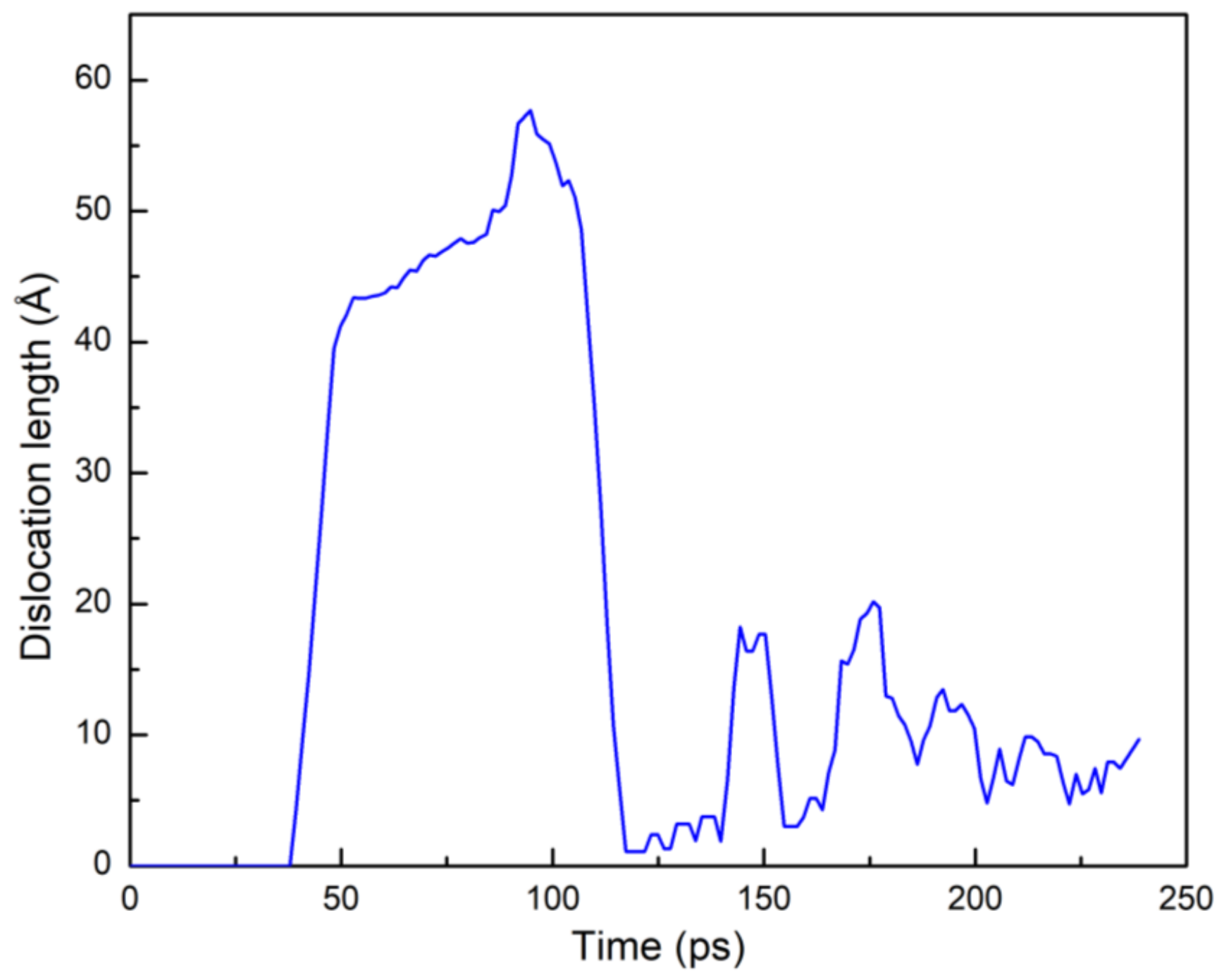

Figure 17

Total dislocation length during the rolling process at $10 \AA$ depths, rolling at $50 \mathrm{rad} / \mathrm{ns}$ and moving at 1.0 $\AA ̊ n$ ps. 


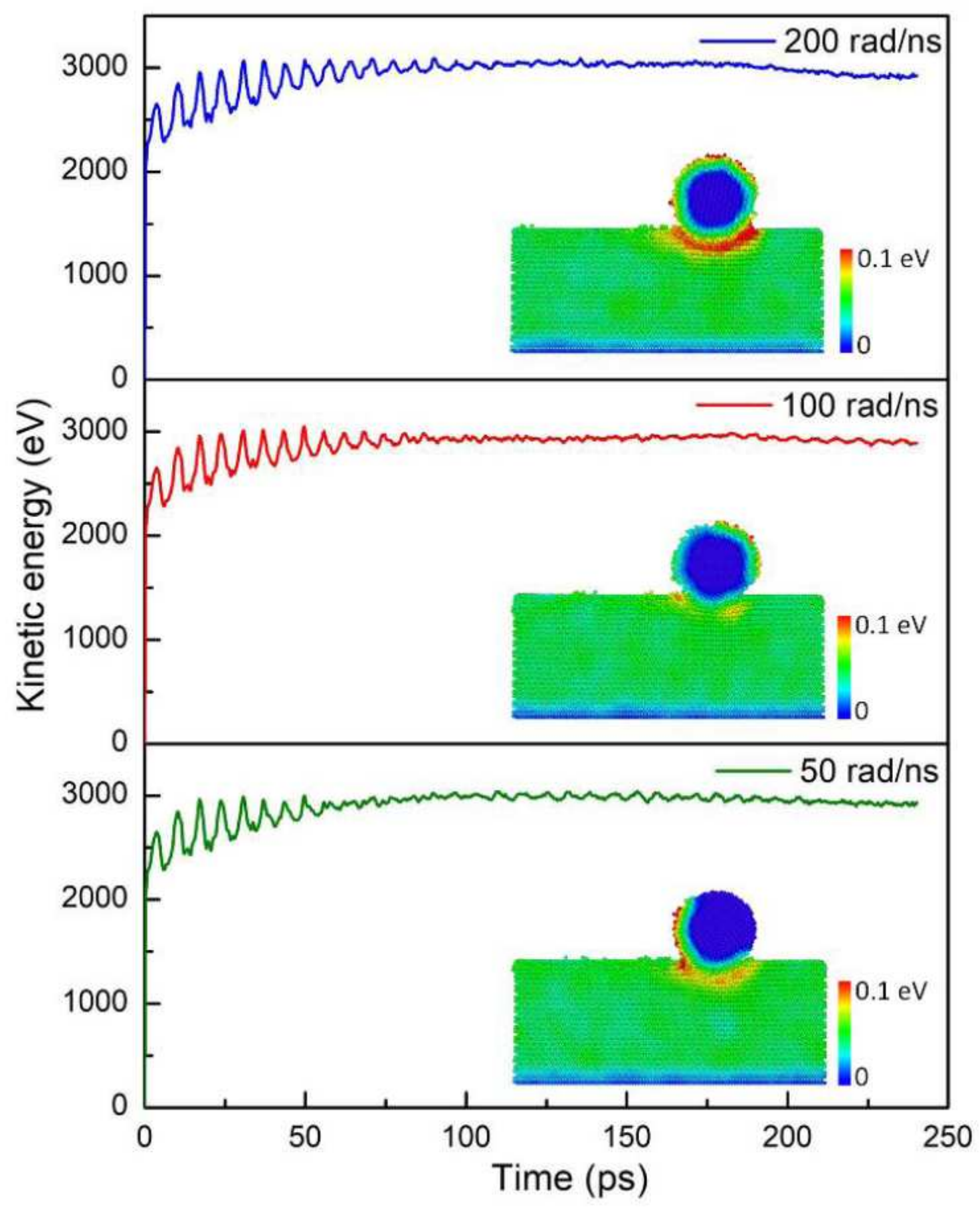

Figure 18

Total kinetic energies and kinetic energy distribution at different velocities at $5.0 \AA$ depth, moving at 1.0 $\AA / p s$ in rolling motion. 


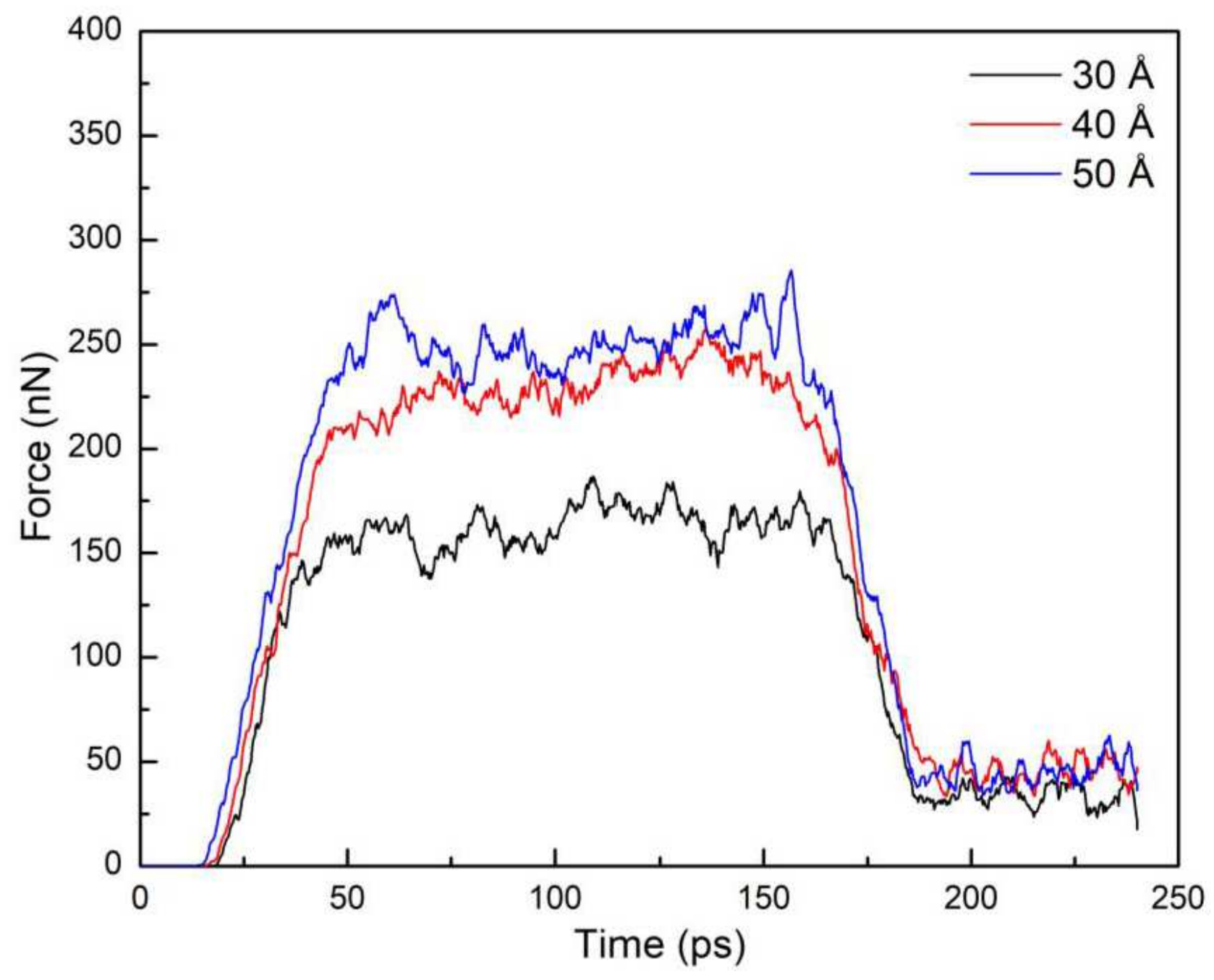

Figure 19

Total forces of different abrasive sizes at $1.0 \AA ̊ / p s$ and $5.0 \AA$ depth. 
(a)

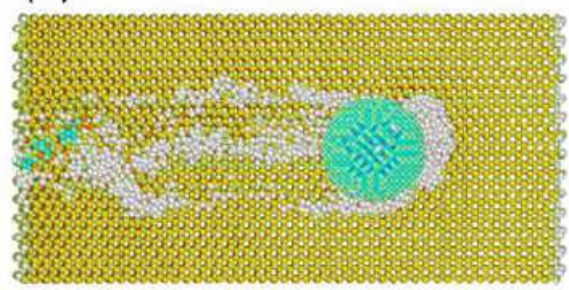

(b)

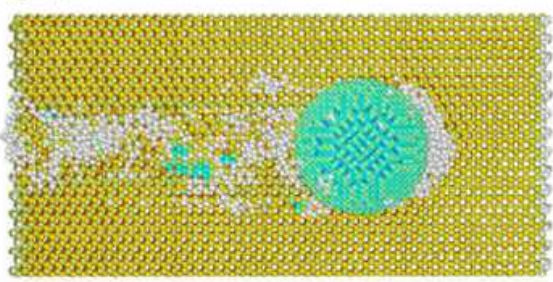

(c)

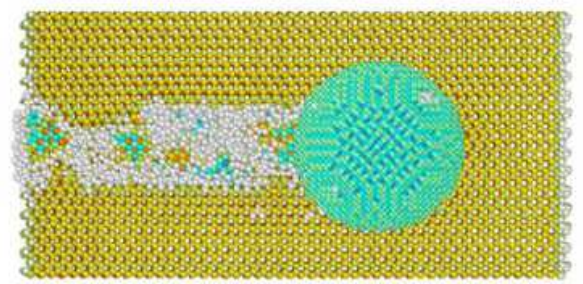

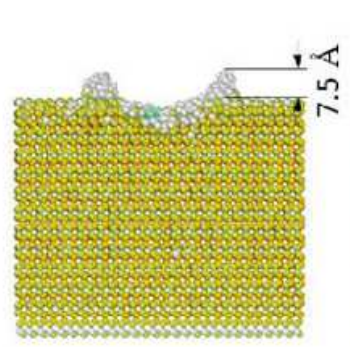
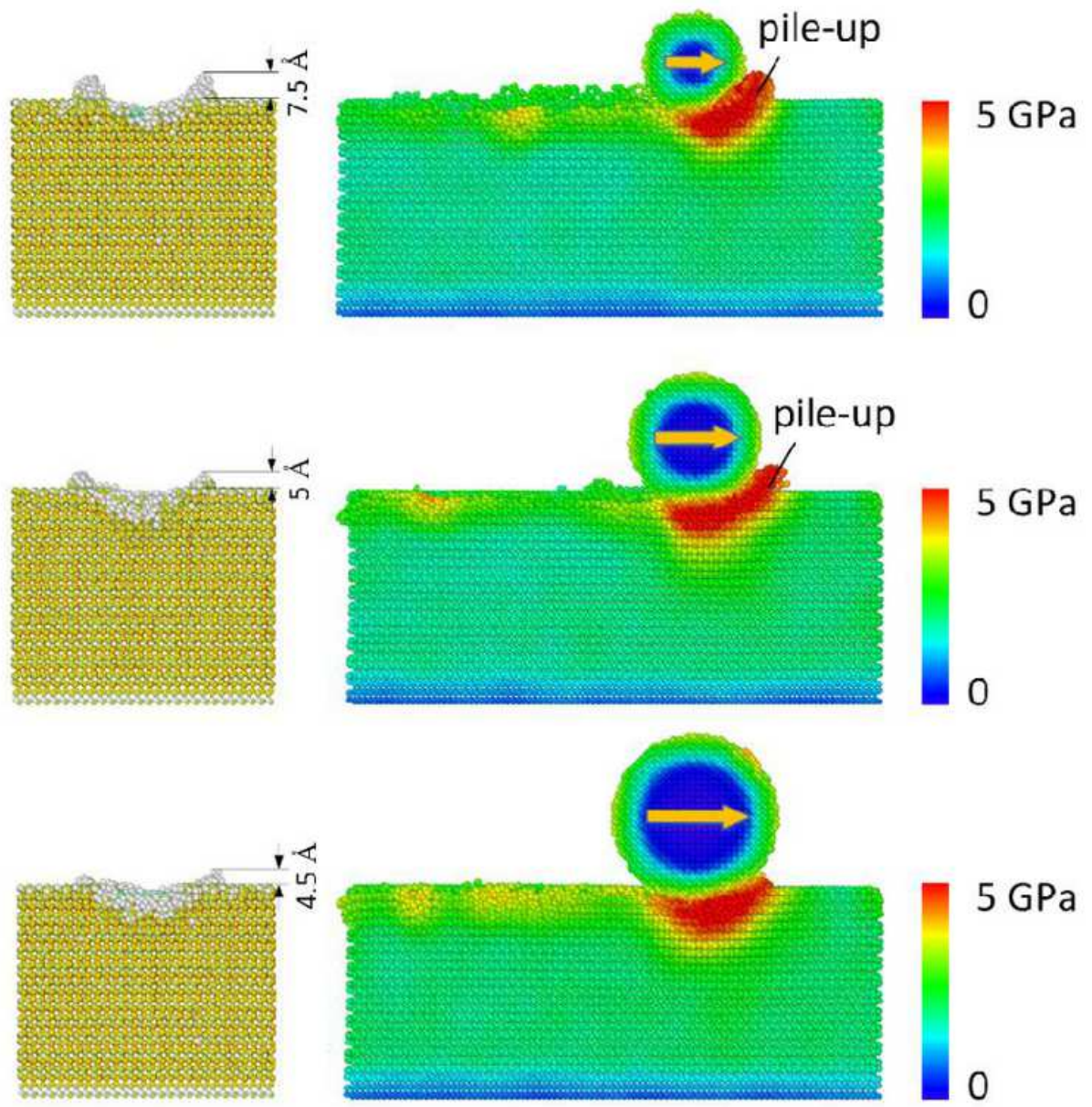

Figure 20

Surface morphology and von Mises stress distribution of different abrasive sizes sliding at $1.0 \AA / p s$ and 5.0 Å depth: (a) $30 \AA$, (b) $40 \AA$, and (c) $50 \AA$. 
(a)
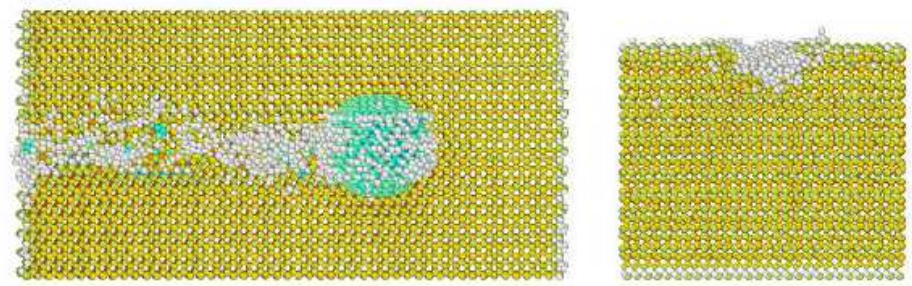

(b)
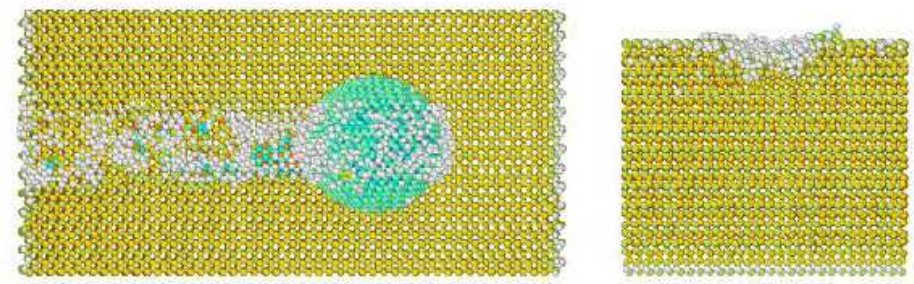

(c)
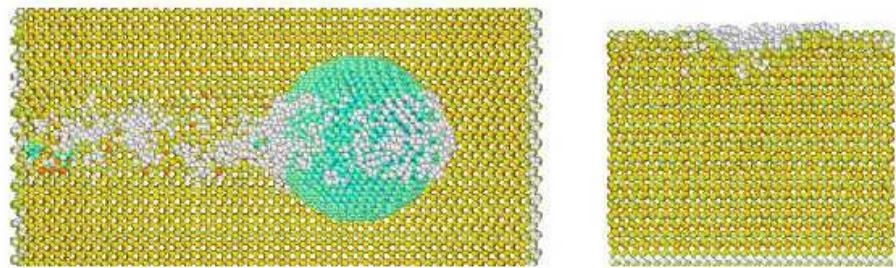
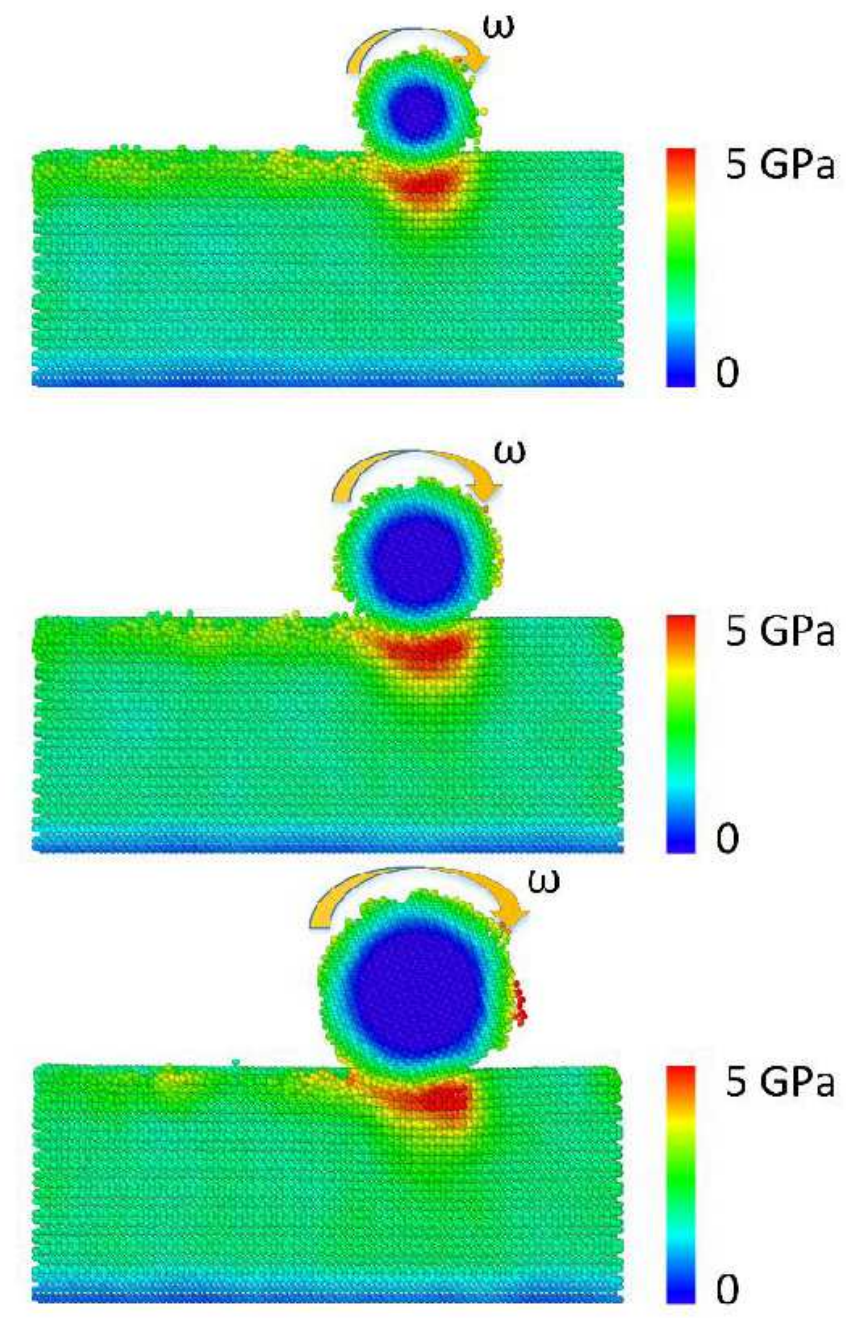

\section{Figure 21}

Surface morphology and von Mises stress distribution of different abrasive sizes rolling at $50 \mathrm{rad} / \mathrm{ns}$, moving at $1.0 \AA$ /ps and $5.0 \AA$ depth: (a) $30 \AA$, (b) $40 \AA$, and (c) $50 \AA$. 


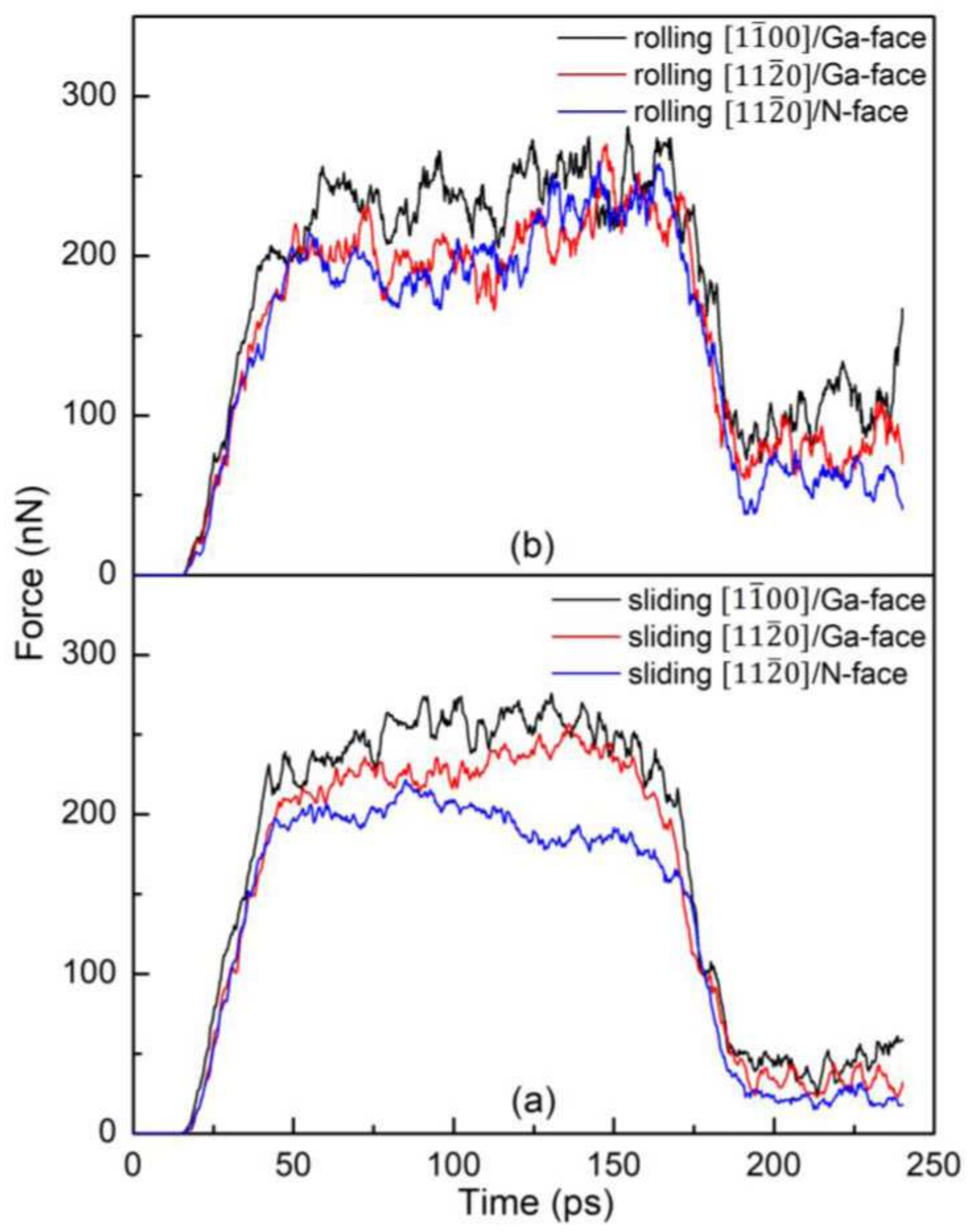

Figure 22

Total forces of different polishing direction and face at $1.0 \AA$ /ps and $5.0 \AA$ depth: (a) sliding motions, and (b) rolling motions. 
(a)
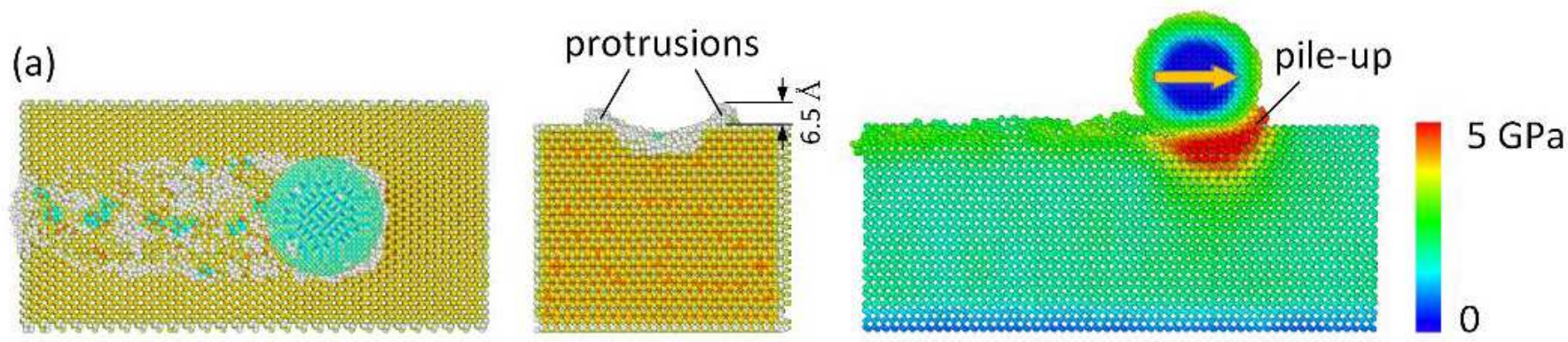

(b)
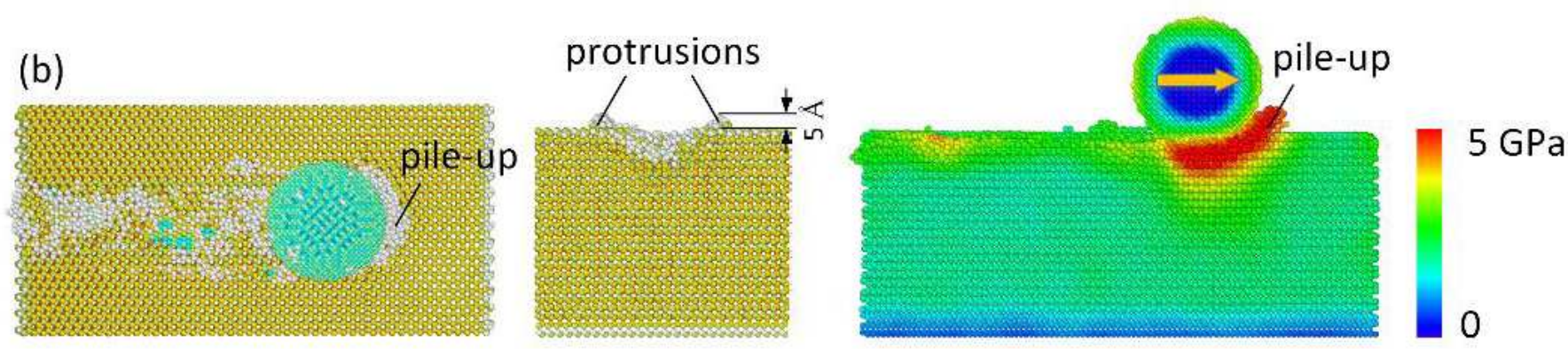

(c)
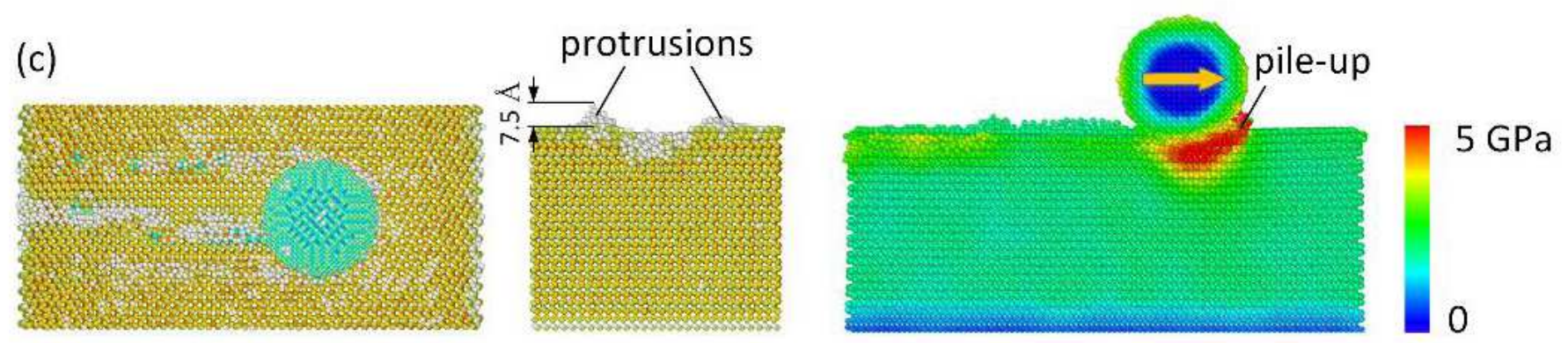

Figure 23

Surface morphology and von Mises stress distribution of different sliding directions and faces, sliding at $1.0 \AA$ Åps and $5.0 \AA$ A depth: (a) [1-100] direction/Ga-face, (b) [11-20] direction/G-face, and (c) [11-20] direction/ $\mathrm{N}$-face. 
(a)
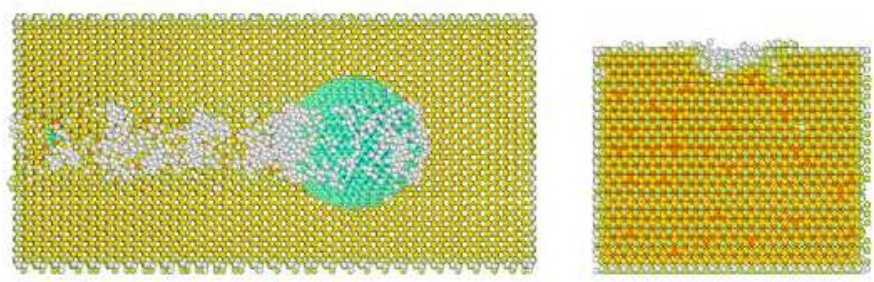

(b)
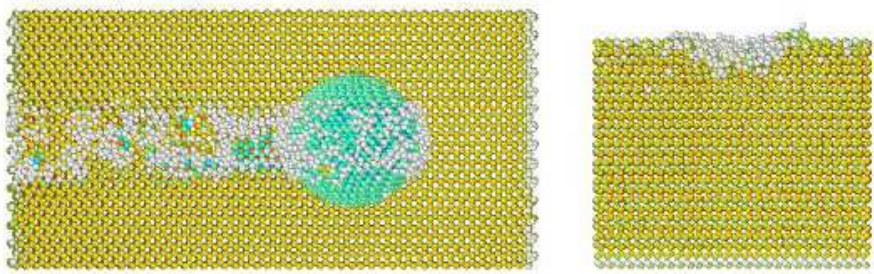

(c)

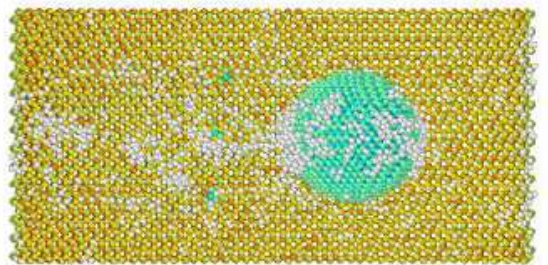

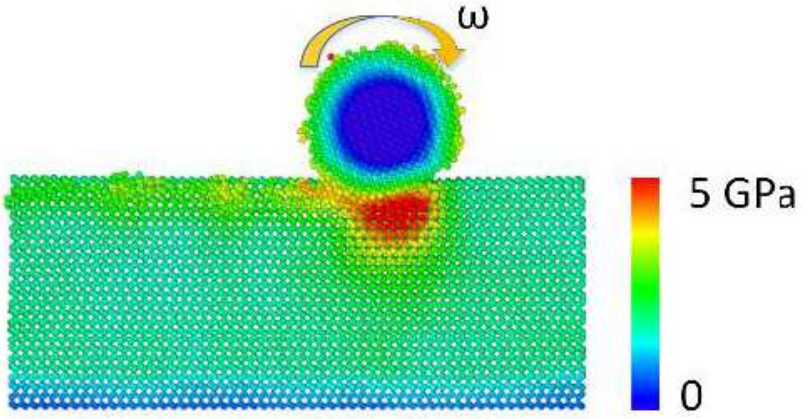

$\omega$
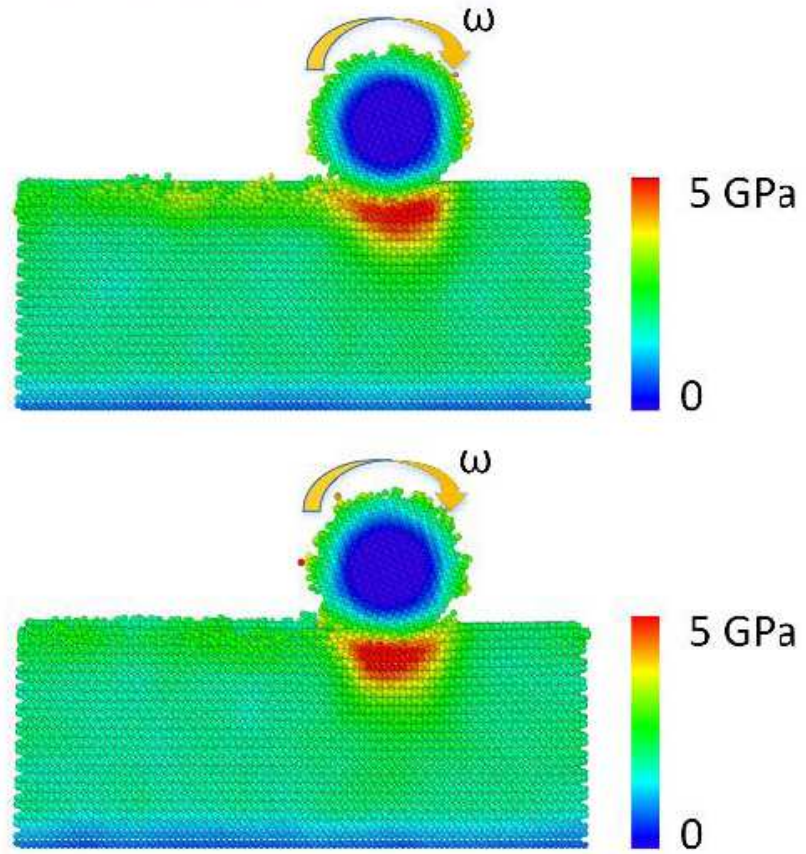

\section{Figure 24}

Surface morphology and von Mises stress distribution of different rolling directions and faces, rolling at $50 \mathrm{rad} / \mathrm{ns}$, moving at $1.0 \AA$ Aps and $5.0 \AA$ A depth: (a) [1-100] direction/G-face, (b) [11-20] direction/G-face, and (c) [11-20] direction/N-face. 